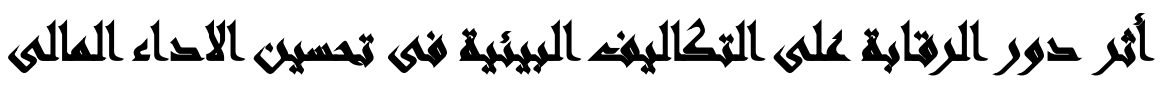

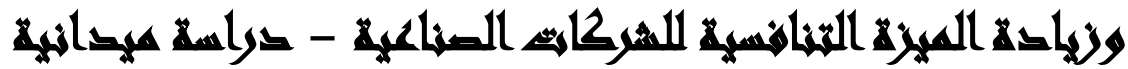

[rr]

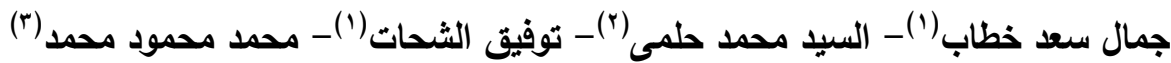

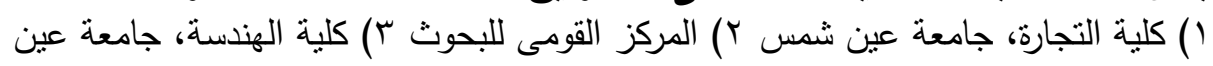

شيمس

\section{المستخلصن}

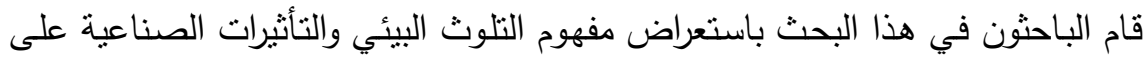

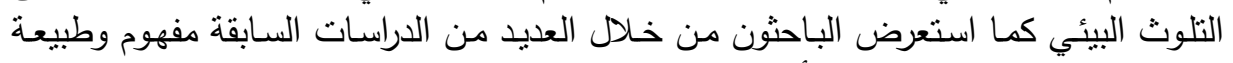

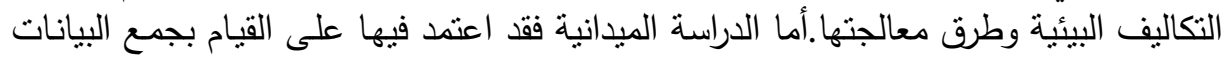

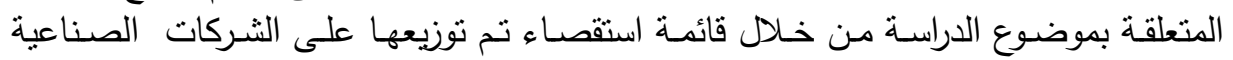

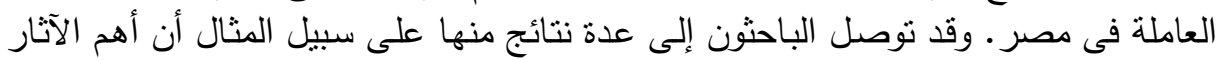

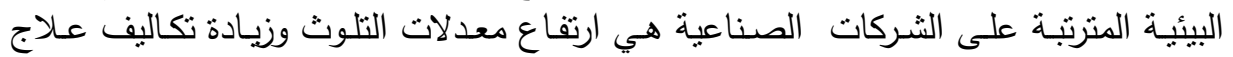

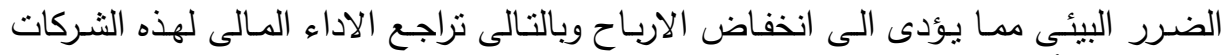

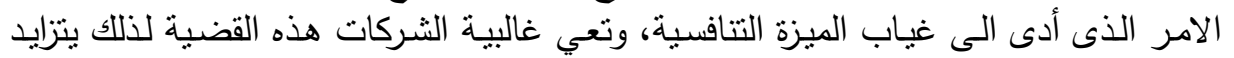

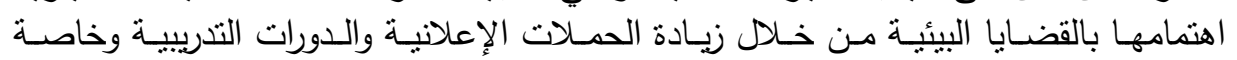
لموظفيها للوعي بهذه القضية.

كما أن غالبيـة هذه الشركات لا توجد بها إدارات متخصصـة للاهنمام بالتكاليف البيئية

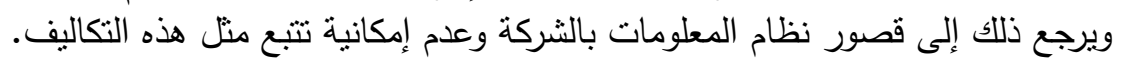

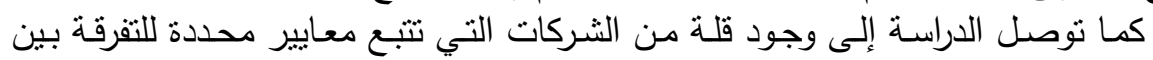

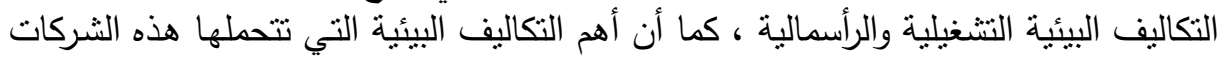
تتمنل في تكاليف الحماية والحد من التلوث البيئى.

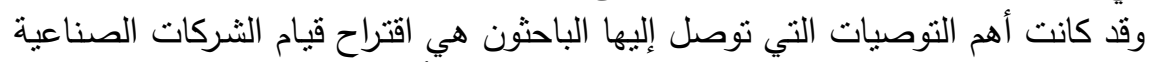

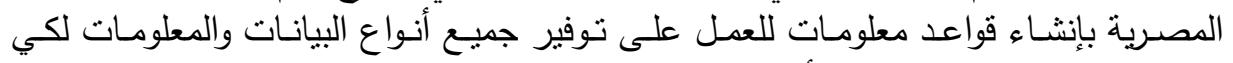

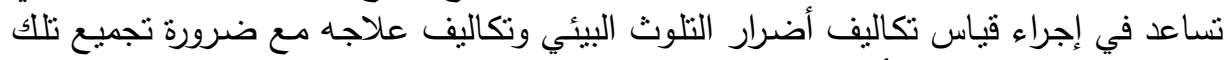

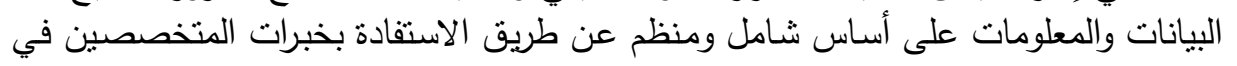

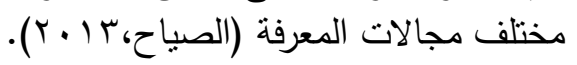




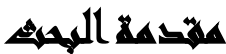

أصبح الاهتمام الحالي بالمحافظـة على البيئة وتجنب مسببات التلوث وإعادة صيانة وترميم البيئة ذا أهمية كبيرة لمختلف فئات المجتمع ،حيث أصبح التوجه نحو حمايـة البيئة ومحاولتة منع التدهور البيئي النـاجم عن التلوث محط اهتمام الإنسـان الذي بدأ يقلق على آلى مستقبل حياته لذلك بدء يتجها نحو الاهتمام بالبيئة ،ويبذل الجهود في محاولة تقليل آثاره

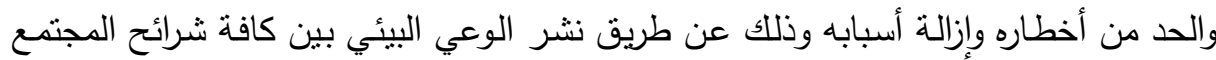

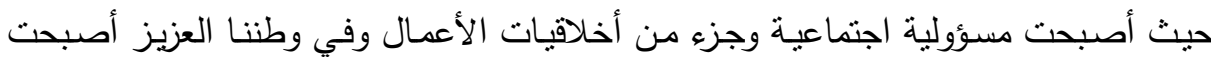
البيئة ومـا تحمله من كوارث من اكبر الأخطار التي يواجهها المجتـع والتي أصبحت فيها

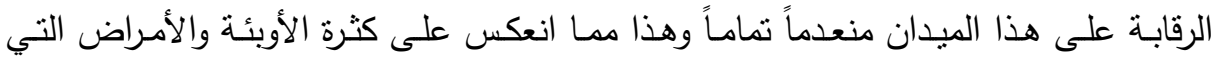

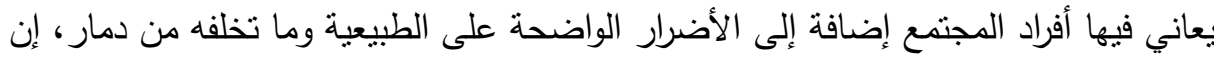

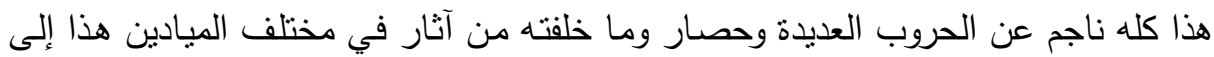

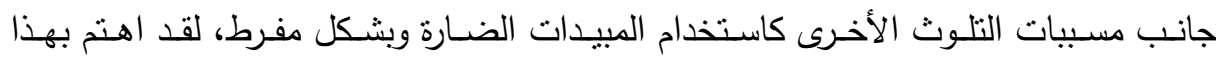
الموضـوع البـاحثون وعلى مختلف اختصاصـهم الطبيـة والهندسية والبيولوجيـة والقانونيـة كل

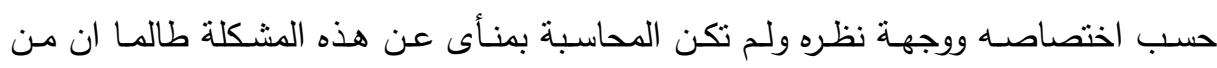
واجبها تحليل البيانات وتقديم المعلومات ووضع نظم للتقارير وخطط عمل للوحدات المختلفة ومتابعة مستوى الالنزام بها .(Uyar, Alim,2012)

\section{And}

أصبحت حماية البيئة هاجساً دولياً، كما أن الإنفاق لحماية البيئة في نزايد مستمر ، من

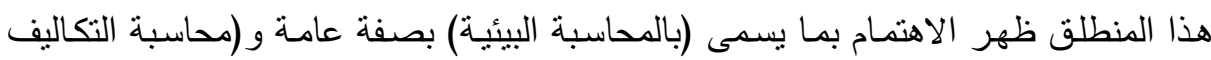
البيئية) بصفة خاصـة وذلك لتوفير المعلومات المالية المتعلقة بالنواحي البيئية للاستفادة منها

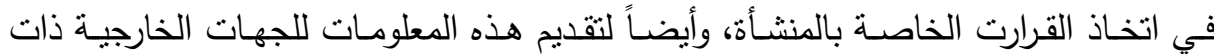
العلاقة منل " وكالات حماية البيئة " 
وتتشير إحدى الدراسـات التي تبنتها وكالـة حمايـة البيئة الامريكيـة إلى أهيـة التركيز على

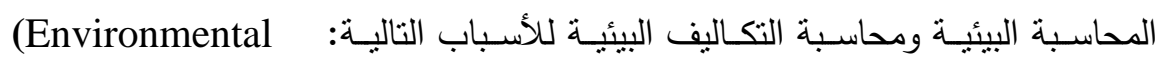
protection agency, environmental accounting project, 2009) • أن الكثير من التكاليف البيئية يمكن تخفيضها أو حتى تجنبها نهائيا ذً نظراً لكون هذه التكاليف لا تضيف أية قيمة للمنتجات.

• أن هذه التكاليف قد تكون مدمجة ضمنياً ضمن التكاليف غير المباشرة، أو ينم تجاهلها

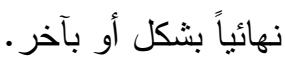

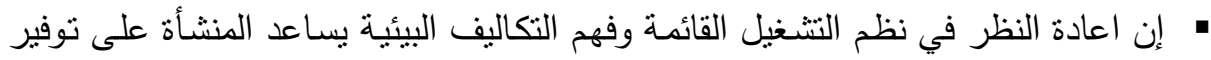
معلومات أدق للمنشأة عن التكاليف البيئية ، و تسعير منتجاتها. • تحقيق المنافسة لمنتجات الثركة من خلال الاعلان الترويج لمنتجات ذات مواصفات بيئية أفضل. وفي هذا الإطار سعت هذه الجهود نحو التوجه لقياس التكاليف البيئية والتعرف على طبيعتها ونوعيتها ومعرفة آثارها. وذللك ما اكدته (دراسة سـلام 10 • ب ) بأن الهدف الاساسى للتكاليف الجودة هو العمل على الحد من التلوث والعمل على معالجته وقد توصلت الدراسـة الى ان معظم الثـركات الصناعية التى تهتم بتكاليف الجودة قد وفرت نظام معلوماتى عن تكاليف الجودة وكيفية قياسها، وكذلك كيفية الحد منها لمساعدة متخذى القرارات فى هذه المنشآت على اتخاذ القرارات

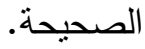
وحول هذا الموضوع أجريت دراسة شارك فيها كل من معهد ( تنلوس) والمعهد الأمريكي

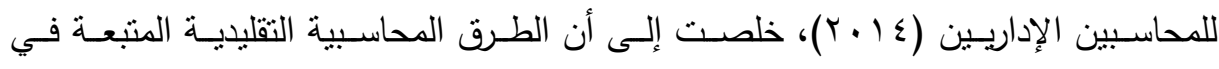
الثركات الصناعية لانتيح في غالب الأمر القدر الكافي من المعلومات حول تكاليف البيئة، ويمكن التعبير عن المشكلة من خلال السؤال الرئيسى التالى: ما مدى وجود دور للمحاسبة البيئة والرقابة على التكاليف البيئية فى تحسين الاداء المالى التئي

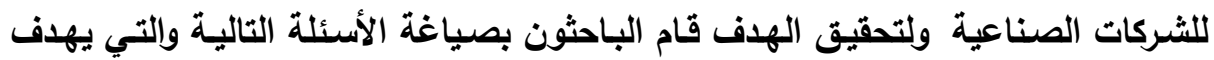




\section{أسئلا الهمبه}

ا. مـا طبيعـة التكاليف البيئيـة في الثـركات الصـناعية، وتحت أي بند مـن البنود تتـدرج التكاليف البيئية؟

r. ما أوجه الإنفاق لأنشطة حماية البيئية التي تتحملها الثركات الصناعية لتقليل الخطر؟

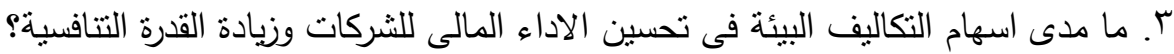
؛. مـا مدى فعاليـة التكاليف البيئية ودورهـا في توفير المعلومـات الملائمـة لاتخـاذ القرارات

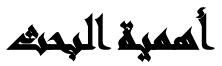

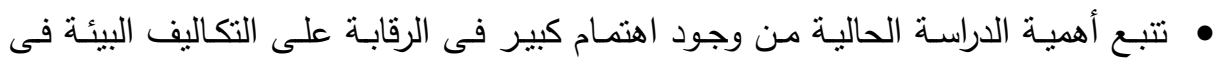

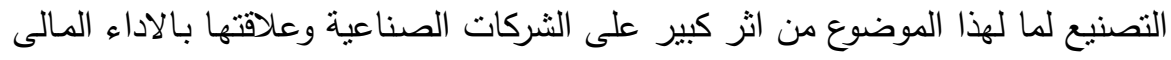
ل الشركات.

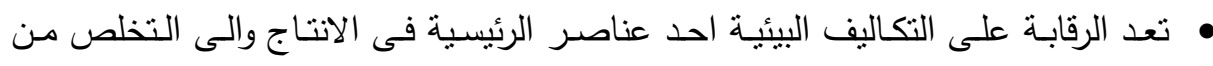

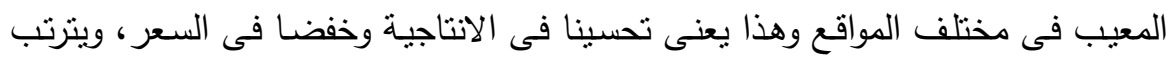

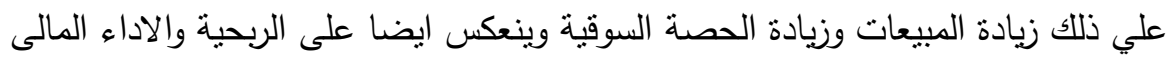
وزيادة القدرة التنافسية للشركات الصناعية.

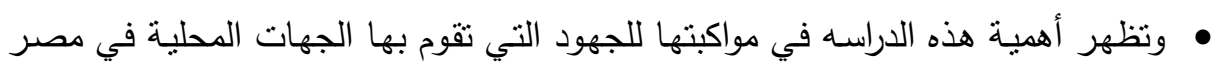
(جهات حكومية ومهنية) • كما تستمد الدراسة أهميتها من أنها تأني في ظل الجهود التي تقوم بها الحكومة المصرية

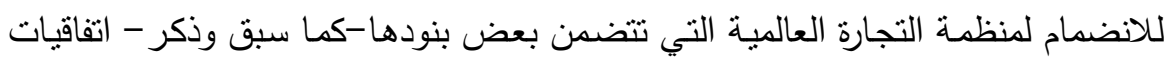
لحماية البيئة للدول الراغبة في الانضمام لعضوية هذه المنظمة.

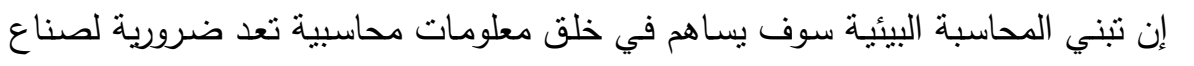
القرارات. 


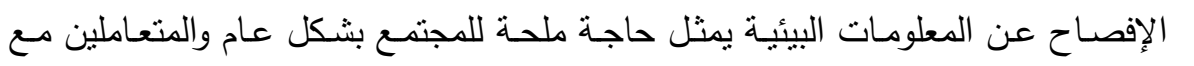
الثركة بوجه خاص.

$$
\begin{aligned}
& \text { هبيان مدى موائمة موقف الثركة مع المبدأ القانوني "من يلوث يدفع". } \\
& \text { • إبراز دور الثركة في تقليل المخاطر الناجمة عن النلوث. }
\end{aligned}
$$

\section{إضافة إلى ما سبق هناك عدة عوامل ساهمت في الاهتمام بهذا الجانب منها:}

ا. تغير الاتجاه السائد نحو وجهة النظر التي تقتضي بضرورة تحمل التهل الوحدة بنكاليف

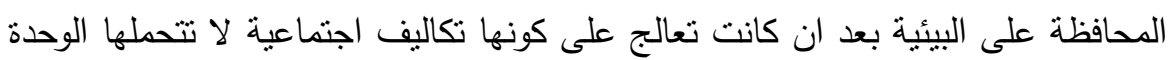

$$
\text { وبالتالي يتم معالجة هذه البيانات من خلال الوظيفة المحاسبية. }
$$

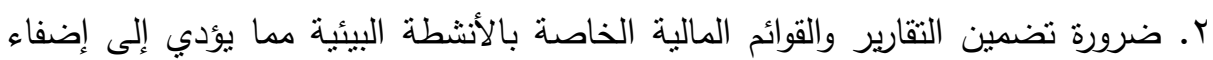
الثقة في البيانات المحاسبية إضافة إلى تلبية حاجات المجتمع من المعلومات الخاصة بالأنشطة البيئية.

r. المساهمة في إعداد تقارير تكاليف النلوث البيئي على المستوى القومي والذي يفيد في الحصول على المؤثرات التي تمكن من متابعة التلوث الناتج عن الأنشطة المختلفة

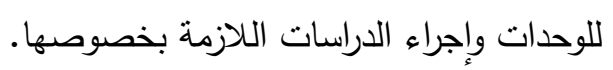

\section{أهسا هم المهمه}

$$
\text { يهذف البحث إلى: }
$$

ا ـ إمكانيـة إعداد معلومـات محاسبية تعبر عن المسؤولية البيئية للثـركات الصناعية، من

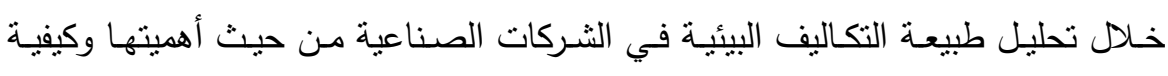

$$
\text { المحاسبة عنها، ودورها في تحسين الاداء المالى للشركات الصناعية. }
$$

r. التعرف على مدى فاعلية المعلومات البيئية وخاصـة المحاسبية منها في صنع القرارات

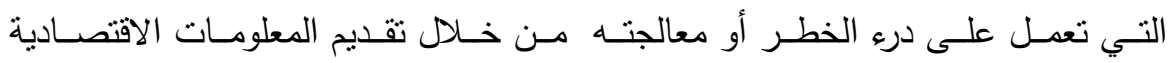
والمحاسبية اللازمة لذلك. 
r. التأصيل العلمي لمفهوم المحاسبة عن التكاليف البيئية والرقابـة عليها، وتوضيح مدى

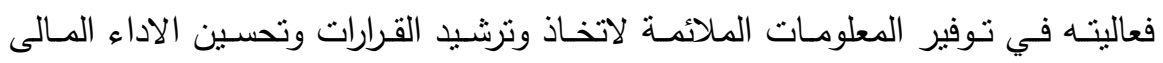
للشركات الصناعية وزيادة القدرة التتافسية للشركات. ؛. التعرف على دور الوحدة الاقتصـادية في تقليل المخـاطر الناجمـة عن التلوث البيئسي بالنسبة للعاملين وأفراد المجتمع والبيئة.

\section{هزور الهمهي}

فرض الاراســة الرئيسـى: لا يوجد دور ذو دلالـة معنويـة للتكاليف البيئية فى تحسين

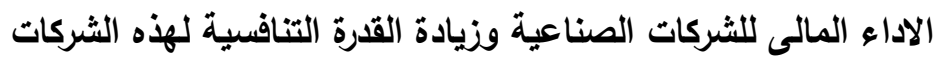
يشتق منها فروض الدراسة الفرعية التالية: ' . لا يوجد دور ذو دلالة معنوية لتكاليف الوقاية فى تحسين الاداء المالى للشركات الصناعية وزيادة القدرة التتافسية لهذه الثركات. r. لا يوجد دور ذو دلالة معنوية لتكاليف التقييم فى تحسين الاداء المالى للثركات الصناعية وزيادة القدرة التنافسية لهذه الثركات. r. لا يوجد دور ذو دلالـة معنويـة لتكاليف الفشـل الداخلى فـى تحسين الاداء المـالى للشـركات

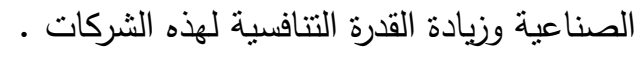
ع. لا يوجد دور ذو دلالة معنويـة لتكاليف الفشـل الخارجى فى تحسين الاداء المـالى للشركات الصناعية وزيادة القدرة التتافسية لهذه الثركات.

\section{مبوض القواسمة}

تتحدد حدود الدراسة الحالية على النحو التالى:

الحـدود المكانيـة: اقتصـرت الدراسـة الحاليـة على القطاع الصناعي، لأن مشكلة التلوث

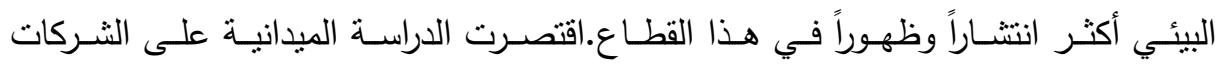


الصناعية بدينة العاشر من رمضان التي تعدُّ واحدة من أكبر الددن الصناعية بمصر ، نظراً لما تتضمنه من منشآت صناعية تختلف باختلاف أحجامها وأنثطنها.

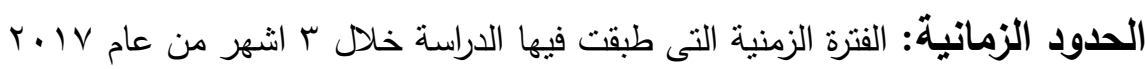
الحدود البشرية: وتتضمن كافة الدديرين الماليين والمحاسبين العاملين فى الثركات الصناعية العاملة فى مصر بالإضافة الى مديرى الانتاج والجودة العاملين فى الثركات.

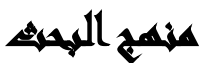

تعدُ هذه الدراسة ميدانية استكثافية، إذ سنقوم الباحثون بمسح نظري لأهم الكتابات التي لئي

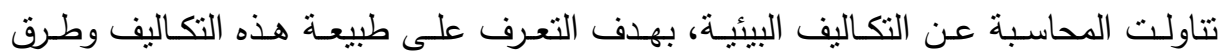

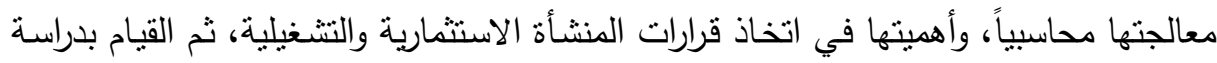

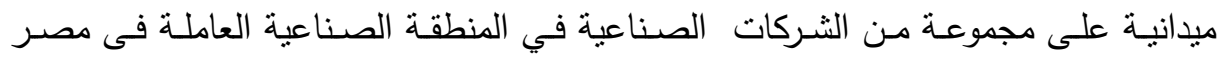

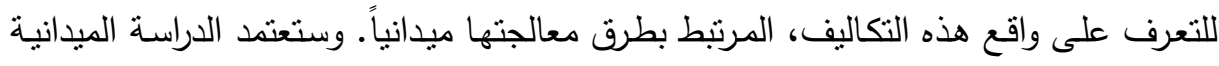

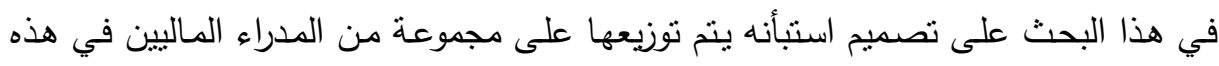

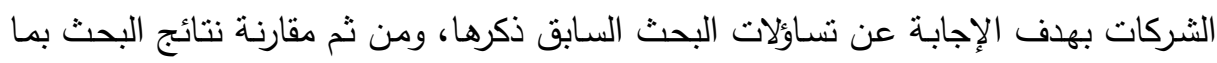
سبق التوصل إليه في الدراسات السابقة. وسيتم تحليل البيانات باستخدام الأساليب الإحصائية

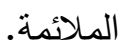

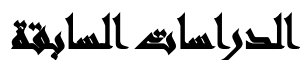

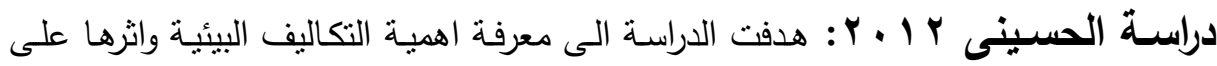

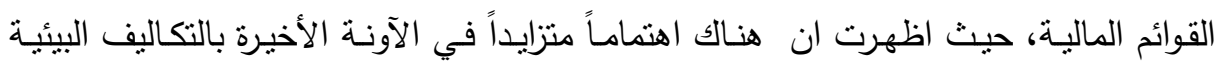
وكيفية قياسها واظهارها في القوائم المالية، وإدخالها ضمن عملية انخان التاذ القرارات وتقيبيم الأداء.

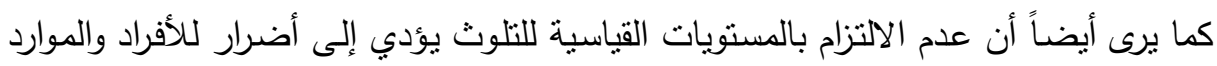

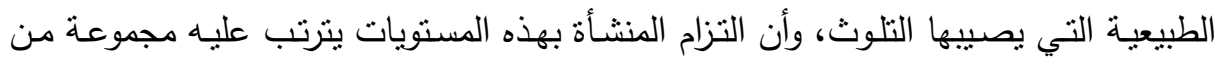
النكاليف البيئية يتمتل عائدها في منفعه يحصل عليها المجتمع. وقد أثنار إلى أسباب الاهتمام

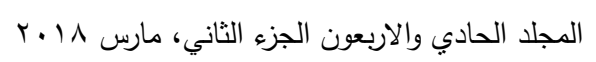


بالتكاليف البيئية وهي أنها كبيرة ومتزايدة ومبعثرة، كما أنها لاتؤخذ في الاعتبار عند فحص ودراسة أب مشروع جديد.

دراسـة نور (7 1 Y): هدفت الدراسـة الى الكثف عن أهمية التكامل بين إدارة الجودة الثـاملة وتقنيات إدارة التكلفة فى تحسين الاداء فى الثـركات الصناعيـة المسـاهمة العامـة الأردنية وتوصلت الدراسة الى نتائج عدة من أهمها وجود أثر لعناصر إدارة الجودة الثـاملة

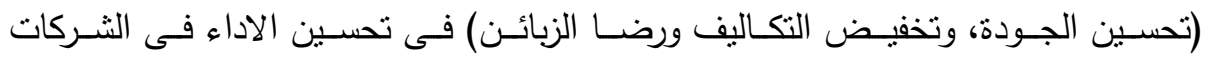

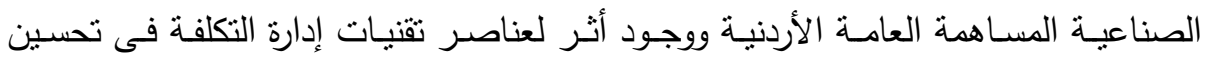

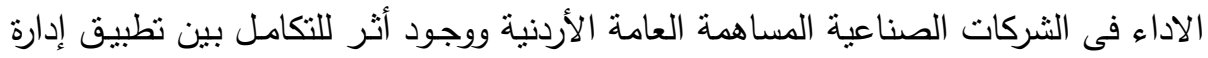
الجودة الثـاملة مـع استخدام تقنيات إدارة التكلفة فى تحسين الاداء فى الثركات الصناعية المساهمة العامة الاردنية. وقدمت الدراسة عدداً من التوصيات أبرزها ضرورة استمرار الثركات الصناعية المساهمة العامة الاردنية فى تطبيق نظام إدارة الجودة الثشاملة وتطبيق تقنيات إدارة التكلفة،

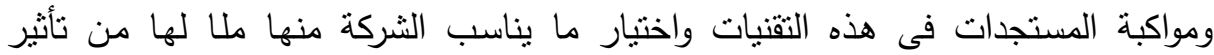
إيجابي فى تحسين أدائها.

دراسة حمزات( ( 1 ـ Y): هدفت الدراسة إلى التعرف على أثز تطبيق نظام إدارة الجودة الثاملة ضمن المنشآت الصناعية المستخدمة لمدخل التكلفة المستهدفة، وبيان الاثار الايجابية المنتظرة من ذلك و المتمثلة في المساعدة على إدارة التكاليف بشكل أفضل الامر الذي يمّكن تلك المنشآت من الصمود في سوق المنافسة. كما هدفت الى دراسة واقع المنشآت الصناعية السورية محاسبيا و اداريا في محاولة لإعادة هيكلة الانظمة التكاليفية بشكل متكامل مع مفاهيم نظام إدارة الجودة الثاملة كخطوة داعمة لتخفيض التكاليف وإدارتها وتدعيم هذه المنشآت،بالإضافة إلى تقديم مجموعة من لإنه التوصيات والمقترحات في ضوء النتائج التي تم التوصل اليها. وتوصلت الدراسة إلى أنه يمكن للمنشاة أن تطبق كل من مدخل التكلفة المستهدفة ونظام

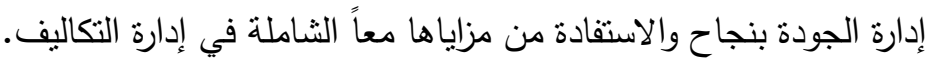

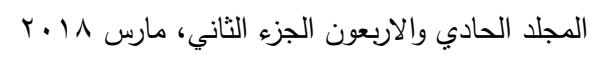


كما توصلت إلى مجموعة من النتائج الفرعية أهمها أن اتصاف بيئة التصنيع الحديثة بحده المنافسة وصعوبة التحكم بالأسعار جعلت أنظمة التكاليف التقليدية غير ملائمة وعاجزة عن توفير المعلومات بالدقة والوقت الملائم لذا كان لا بد من التحول نحو المداخل المحاسبية

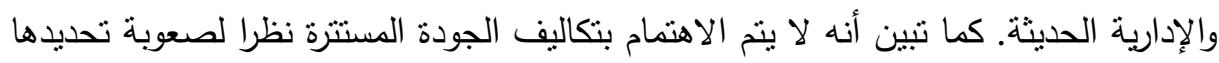
وقياسيا بدقة ولا يتم إعداد نقارير محاسبية خاصة بالتقرير عن تكاليف الجودة في المنشآت التهات

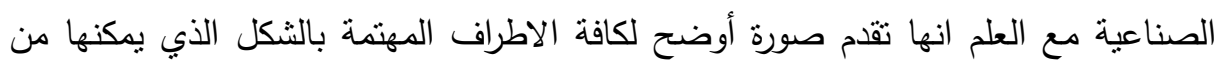
اتخاذ القرارات بطريقة أفضل. كما نم التوصل إلى أنه كلما زاد الانفاق على أنشطة الوقاية ستخفض كل من تكاليف التقييم وتكاليف الفتل الداخلي والخارجي. وبما أن تكاليف الجودة تعد جزء من التكاليف الكمية فإن تخفيضها سينعكس حتما على ولى التكلفة الكلية.

\section{الاطار اللنظلره}

أولاً: تكاليف رقابة الجودة: وتتضمن جميع التكاليف المرتبطة بالأنشطة اللازمة لضمان

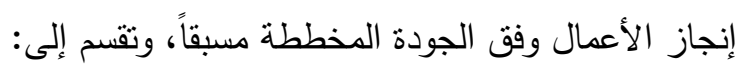

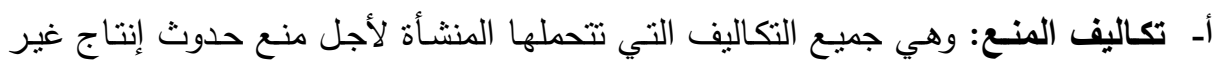

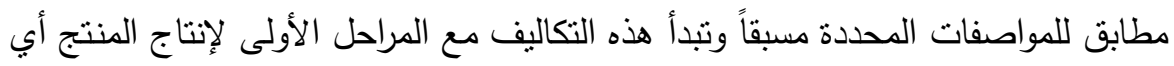

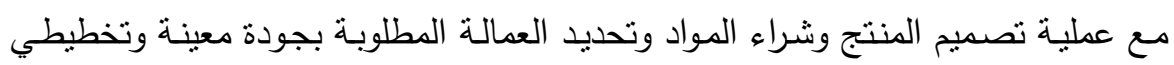
الأنشطة اللازمة للتحقيق من صلاحية المنتج.

بـ تكاليف الفحص والتقويم: تشمل تكلفة جميع النشطة المرتبطة بفحص وتقويم مدخلات

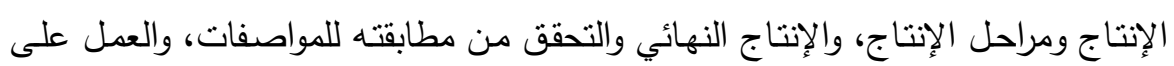
منع شحن الإنتاج المعيب إلى العملاء.

ثانيـا: تكـاليف الفشـل: تتشـأ هذه التكاليف عن قصور أنشطة رقابـة الجودة في تحقيق مستوى الجودة المستهدف، وتتقسم إلى:

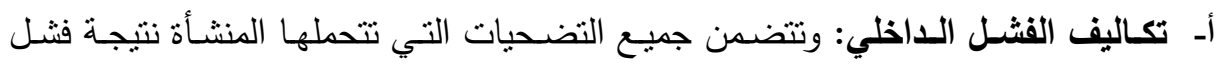
أنشطة رقابة الجودة في أداء وظائفها وفقاً لبرامج مراقبة الجودة المخططة خلال المراحل

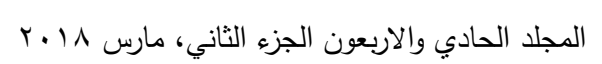


المختلفة من وقت استلام مستلزمات الإنتاج من الموردين حتى تسليم المنتجات (سلع أو خدمات) للعملاء.

بـ تكاليف الفشل الخارجي: وتتضمن جميع التضحيات التي تتشأ من قصور أنشطة المنع

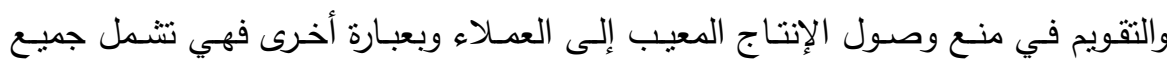
التضحيات التي تترتب على وفاء المنتج (سلعة أو خدمة) باحنياجات ورغبات العملاء. الميزة التتافسية: تتحقق الميزة التنافسية للشركات عن طريق انتاج منتجات بأعلى جودة واقل تكلفة وذلك من اجل تحقيق رضا العملاء فى السوق وبالتالى تزداد حصة الثركة فى السوق وتستطيع الثركة تحقيق اعلى ربحية.

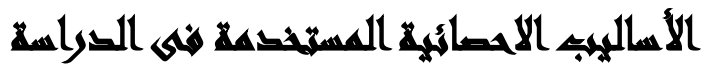

منهجيـة الاراسـة: تعتبر منهجيـة الدراسـة وإجراءاتها محوراً رئيساً يتت من خلاهها إنجاز الجانب النطبيقي مـن الدراسـة، فعن طريقها يتت الحصـول على البيانـات المطلوبـة لإجـراء التحليل الإحصائي للتوصل إلى النتائج التي يتم تفسيرها في ضوء فرئ أدبيات الدراسات المتعلقة بموضوع الدراسـة، وبعد ذلك تطوير الاستبانة بما يتتاسب مـع البيانات المستهدفة من اجل الوصول الى نتائج وتوصيات حول اثر دور الرقابة على التكاليف البيئية فى تحسين الاداء المالى وزيادة الميزة التتافسية للشركات الصناعية المصرية مقدمة: يتتاول هذا الفصل وصفاً للمنهج المتبع لتحقيق أهداف الدراسة، كذللك وصفاً لأفراد مجتــع الدراســة وعينتهـا، وكذللك توضيح لأداة الدراسـة المسـتخدمة، وصـدقها وثباتها،كمـا يتضمن وصفاً للإجراءات التي قام ابه الباحث في تقنين أدوات الدراسـة وتطبيقها، وأخيراً المعالجات الإحصائية الني اعتمد الباحث عليها في تحليل الدراسة. منهجيـة الاراسـة: يمكن اعتبار منهج البحث بأنه الطريقة التي ينتبع الباحث خطاهـا، ليصل في النهاية إلى نتائج تتعلق بالموضوع محل الدراسة، وهو الأسلوب المنظم المستخدم لحل مشكلة البحث، إضافة إلى أنه العلم الذي يعني بكيفية إجراء البحوث العلمية. 
ويستخدم كل منهج من المناهج حسب الظاهرة التي يتم دراستها وقد يتم استخدام أكثر من

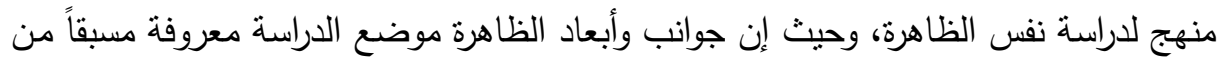

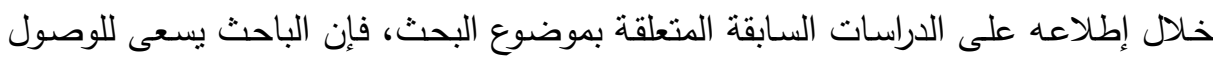

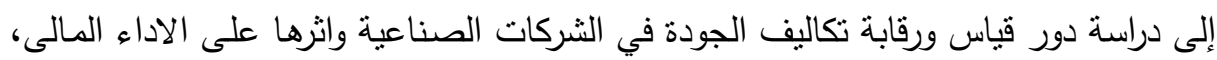

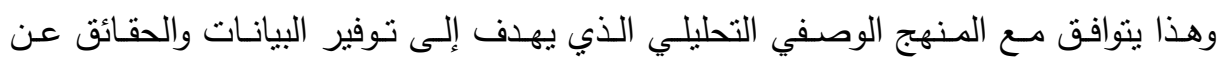
المشكلة موضوع البحث لتفسيرها والوقوف على دلالاتها، وحيث إن المنهج الوصفي التحليلي

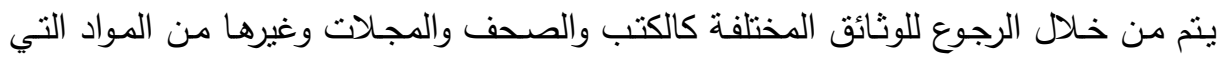
يثبت صدقها بهدف تحليلها للوصول إلى أهداف البحث، فقد نم الإعتماد على هذا المنهج

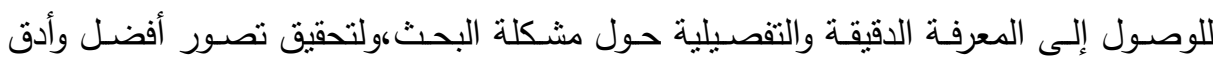
للظاهرة موضع الدراسة، وكذلك استخدم الاستبانة في جمع البيانات الأولية. طرق جمع البيانات: اعتمد الباحث على نوعين من البيانات

البيانات الأولية: وذلك بالبحث في الجانب الميداني بتوزيع استبيانات لدراسة بعض مفردات

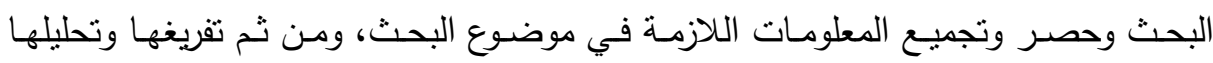

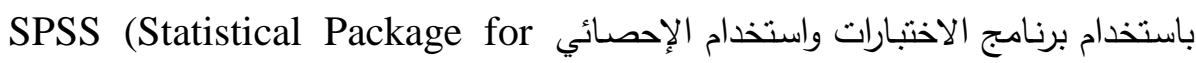
الإحصائية المناسبة بهدف الوصول لالالات ذات قيمة ومؤشرات تدعم موضوع الدراسة.

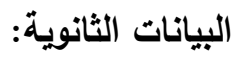
قام الباحث بمراجعة الكتب والدوريات والمنشورات الخاصة أو المتعلقة بالموضوع قيد الدراسة، والتي تتعلق بدراسة واقع الرقابة على تكاليف الجودة من اجل تحسين الاداء المالى للثركات الصناعية، وأية مراجع قد يرى الباحث أنها تسهم في إثراء الدراسة بشكل علمي، الثي، وينوي الباحث

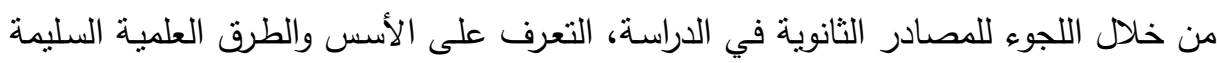
في كتابة الدراسات، وكذلك أخذ تصور عام عن آخر المستجدات التي حدثت وتحدث في مجال الدراسة . 
مجتمع وعينة الاراسة: نم اخذ بع شركة صناعية مسجلة بالبورصة المصرية، لذلك سيتم تطبيق هذه الدراسة على الثركات الصناعة في، والتي يبلغ عددها مب شركة صناعية موزعة في المدن الصناعية المصرية، وقد اعتمد الباحث طريقة المسح الثنامل على مجتمع البحث والتي تتمنل في شركات صناعة المواد الغذائية العاملة في المدن الصناعية فى جمهورية مصر العربية، والتي يبلغ عددها rك شركة صناعية، تم توزيع rك استبانة على جميع

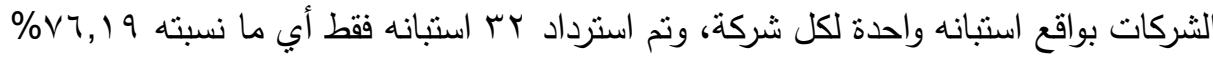

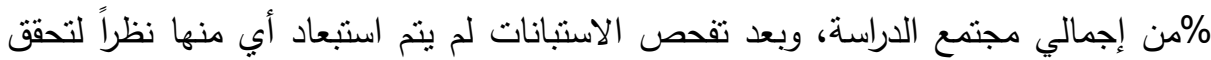

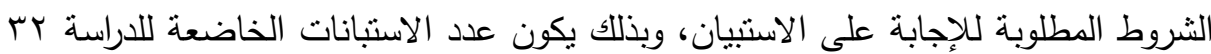

أداة الاراسة: نم تقسيم الاستبانه إلى قسمين كما يلي

• القسم الأول: يتكون من البيانات الثخصية والوظيفية لعينة الدراسة ويتكون من V فقرات

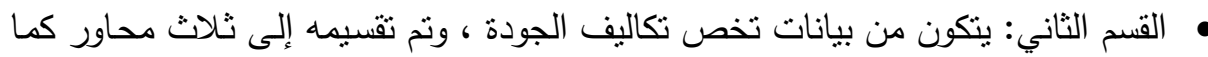
يلي:

الدحور الأول: يتتاول مدى أهية قياس تكاليف الجودة ، وتم تقسمه إلى أربعة محاور فرعية كما يلي : (1) (1) (1) بكاليف الوقاية ويتكون من 1 فقرات

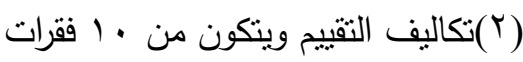

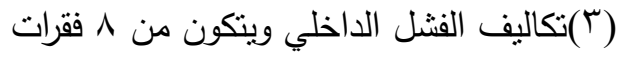
(ع)تكاليف الفنشل الخارجي ويتكون من م فقرات. المحور الثاني: يتتاول مدى تطبيق نظم تكاليف الجودة داخل الثركة واثرها على الاداء المالى للشركات الصناعية، وتم تقسمه إلى أربعة محاور فرعية كما يلي:

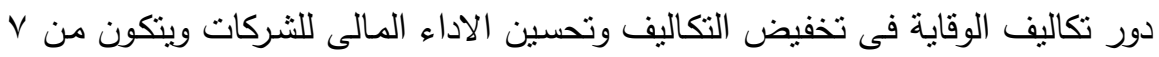


V د دور تكاليف التقييم فى تخفيض التكاليف وتحسين الاداء المالى للثـركات ويتكون من فقرات

• دور تكاليف الفشل الداخلى فى تخفيض التكاليف وتحسين الاداء المالى للشركات ويتكون من V ل فقرات.

هور تكاليف الفتشل الخارجى فى تخفيض التكاليف وتحسين الاداء المالى للشركات ويتكون من > مقرات. وقد كانت الإجابات على فقرات المحاور وفق مقياس ليكرت الخماسي كما هو موضح في:

\begin{tabular}{|c|c|c|c|c|c|}
\hline غير موأ & غير موافَق & محايد & اوأفقق & اوافقي بشدة & التصنيف \\
\hline 1 & $r$ & $\mu$ & $\varepsilon$ & 0 & \\
\hline
\end{tabular}

صدق وثبات الاستبانة: صدق الاستبانة يعني التأكد من أنها سوف تقيس ما أعدت لقياسه

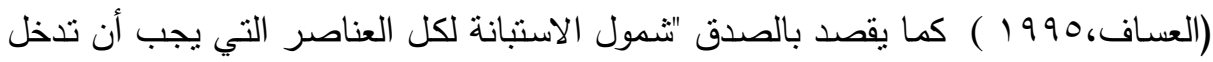

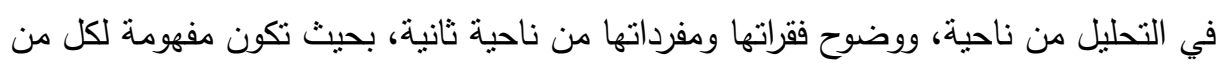

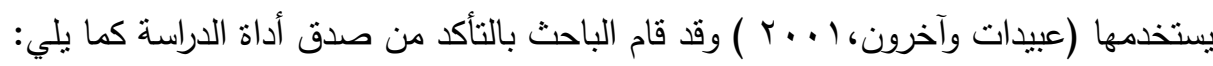

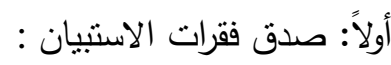

تم التأكد من صدق فقرات الاستبيان بطريقتين،هما :

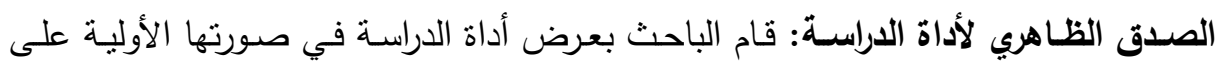

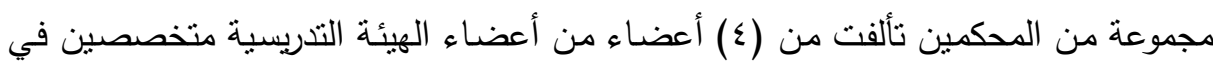
المحاسبة والإدارة والإحصاء.

وتركزت نوجيهات المحكمين على انتقاد طول الاستبانة،كما أن بعض المحكمين نصحوا بضرورة تقليص بعض العبارات من بعض المحاور وإضافة بعض العبارات إلى محاور أخرى. استتاداً إلى الملاحظات والتوجيهات التي أبداها المحكمون قام الباحث بإجراء باء بعاء التعديلات

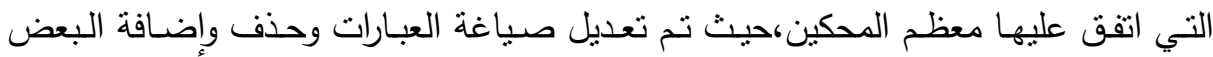
الآخر منها. 
صدق الاتساق الااخلي لفقرات الاستبانة: تم حساب الاتساق الداخلي لفقرات الاستبيان على عينة الدراسة الاستطلاعية البالغ حجمها 38 مفردة،وذلك بحساب معاملات الآنسات الارتباط بين كل

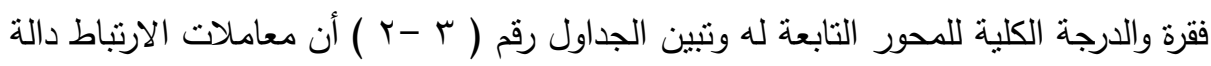

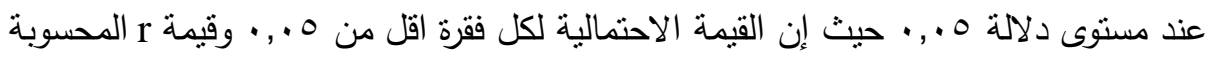

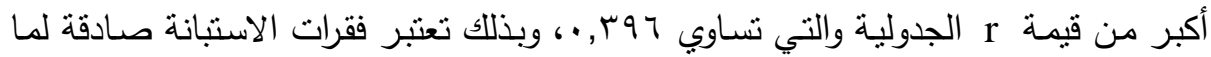
وضعت لقياسه. جدول(ץ): الصدق الداخلى لفقرات مدى اهمية قياس تكاليف الجودة فى تحسين الاداء المالى

\begin{tabular}{|c|c|c|c|}
\hline الاحتمالية & معامل & 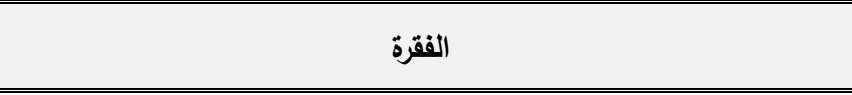 & b \\
\hline & & اولا : تكاليف الوقاية واثرها على تحسين الاداء المالى & \\
\hline$\cdot, \cdot r$ & $\cdot, \wedge \vee \vee$ & يجب قياس تكاليف تصميم المنتجات الجديدة بشكل دقيق & 1 \\
\hline$\cdot, \cdots 1$ & $\cdot, \mathrm{V} r \mathrm{~V}$ & لتجنب قالتوقف تكاليف تقييم إمكانية الاعنماد على الموردين باعتبار أنها ضرورية & r \\
\hline$\cdot, \cdots$ & $\cdot, \mathrm{VTr}$ & العاملين قياس تكاليف قيام الثركة بعقد دورات تدريبية للعاملين لتحسين اداء & $r$ \\
\hline$\cdot, \cdots$ & $\cdot, V \cdot V$ & 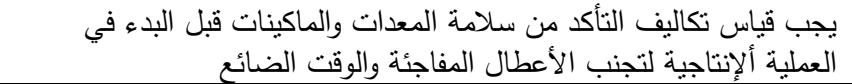 & $\varepsilon$ \\
\hline$\cdot, \cdot r$ & $\cdot$, OVT & استثمارية قياس تكاليف عملية تخطيط تسلسل عمليات الإنتاج باعتبارها تكاليف & $\circ$ \\
\hline$\cdot, \cdots r$ & $\cdot, 70 \mathrm{r}$ & يجب قياس تكاليف التخطيط والتكاليف الناتجة عن تتفيذ هذه الخطط & 7 \\
\hline$\cdot, \cdots$ & $\cdot, \vee>10$ & أنشطة ضبط حساب تكاليف مراجعة نظام الجودة في الثركة، لضمان استمرارية & 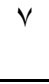 \\
\hline \multirow[t]{2}{*}{$\cdot, \ldots r$} & $\cdot, 797$ & تكاليف الوقاية يمكن اعتبارها تكاليف استثمارية & $\Lambda$ \\
\hline & & ثانبا: تكاليف اتتقييم واثزها على تحسين الاداء المالى & \\
\hline$\cdot, \cdots$ & $\cdot, V Y)$ & مدى مطابقتهاب للمواليف عمليات فحص المواد الخام والنصف مصنعة للتحقق من & 9 \\
\hline$\cdot, \cdots 1$ & $\cdot, \leqslant$, & معبب ؤو تالف معايير محددة من قبل الثركة لتصنيف المنتج كمنتج جيد أو & 1 . \\
\hline$\cdot, \cdots$ & •, Tr & يجب حساب تكلفة تجريب المنتج الجديد قبل طرحة فى السوق & 11 \\
\hline$\cdot, \cdots$ & $\cdot, \wedge) \mathrm{V}$ & يجب حساب تكاليف عمليات واختبارات رقابة الجودة الميدانية للعمليات & it \\
\hline$\cdot, \cdot r$ & $\cdot, \vee \vee 17$ & أخطاء المنتج من قبل العبل اختبل المنتجات قبل تسليمها للعمبل، لتجنب اكتشاف & ir \\
\hline$\cdot, \cdots r$ & $\cdot, V Y)$ & يجب قياس التكاليف أو الخسائر الناتجة عن عدم مطابقة المواصفات & $1 \varepsilon$ \\
\hline$\cdot, \ldots$ &., $70 \leq$ & يجب أن يؤخذ في الاعتبار تكاليف أدوات ومعدات الفحص والاختبار & 10 \\
\hline
\end{tabular}


جمال سعد خطاب وآخرون

تابع: جدول(ץ) - (ب)

\begin{tabular}{|c|c|c|c|}
\hline الاحتمالية & الارتباط & 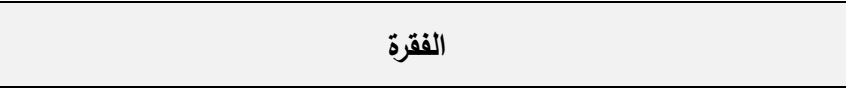 & p \\
\hline$\cdot, \cdots$ & $\cdot, 97 r$ & الإنتاجية حساب تكاليف فحص المواد المخزنة قبل استخدامها في العمليات & 17 \\
\hline$\cdot, \cdots$ & $\cdot, \leqslant 10$ & يجب حساب تكاليف المواد التالفة نتيجة التخزين والتي لا تدخل في عمليات & iv \\
\hline \multirow[t]{2}{*}{$\cdot, \cdots$} & $\cdot, \pi 49$ & تكاليف الوقاية بمكن اعتبارها تكاليف استثمارية & 11 \\
\hline & & ثالثا : تكاليف الفشل الداخلى واثزها على تحسين الاداء المالى & \\
\hline$\cdot, \ldots r$ & $\cdot, \vee 17$ & دقيق وواضح. حساب التكاليف أو الوفورات الناتجة عن سوء تقدير المواد الخام بشكل & 19 \\
\hline$\cdot, \cdots 1$ & $\cdot, V Y I$ & يجب حساب الخسائر الناتجة عن التوقف المفاجئ للعمليات بشكل دقيق. & $r \cdot$ \\
\hline$\cdot, \cdots$ & $\cdot, 70 \leq$ & يجب قياس تكاليف جدولة وإعادة تصميم عمليات الإنتاج بأساليب تضمن & YI \\
\hline$\cdot, \cdots$ & $\cdot, 97 r$ & الأولية كمنتج جديد تكاليف إعادة تصميم المنتجات التي لم تتجح في الاختبارات & rt \\
\hline$\cdot, \ldots r$ & $\cdot, \leqslant 10$ & يجب حساب تكاليف اعادة تصنيع المنتجات المعيبة & rt \\
\hline$\cdot, \cdots$ & $\cdot$, OVY & فيجل في إحدى عمليات التشاليف الناتجة عن التأخير في إيجاد حلول بديلة إذا ما حدث & $r \leq$ \\
\hline$\cdot, \cdots 7$ & $\cdot$, TOY & والتكاليف حساب الإضتافية لتوفير الناتجة عن نقصاد اللازمة المواد التثاء التشغيل عمليات التتغيل & ro \\
\hline \multirow[t]{2}{*}{$\cdot, \cdot r \leq$} & $\cdot, \vee \vee 70$ & يجب حساب التكاليف الناتجة عن أي إخفاق داخلي بشكل دقيق وواضح. & $r y$ \\
\hline & & رابعا: تكاليف الفشل الخارجى واثرها على تحسين الاداء المالى & \\
\hline$\cdot, \cdot \leq r$ & $\cdot, \varepsilon r_{0}$ & جودة منتجاتها. & TV \\
\hline$\cdot, \cdots 1$ & • & المطلوب قياس نكاليف التعامل مع شكاوى العملاء بشكل جدي وإرضائهج بالشكل & $r \wedge$ \\
\hline$\cdot, \cdots$ & $\cdot, \wedge I V$ & إلجاق الضراس تكاليف الدعاوى القضائية المرفوعة ضد الثركة نتيجة حدوث & rq \\
\hline$\cdot, \cdots$ & $\cdot, \times 17$ & 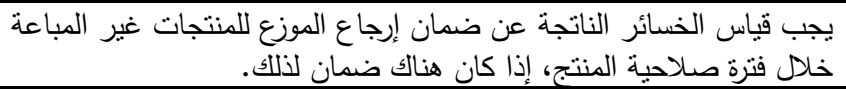 & r. \\
\hline$\cdot, \ldots r$ & $\cdot, V Y I$ & اكتشافها طرف العميل تكاليف أو خسائر تبديل المنتجات المعيبة والتالفة التي يتم & r \\
\hline$\cdot, \cdots r$ & $\cdot, 70 \leq$ & يجب حساب الفرق بين انخفاض حجم المبيعات مقارنة بالسنوات السابقة & rt \\
\hline$\cdot, \cdots$ &., 071 & يجب حساب تكاليف بيع المنتجات بخصم مسموح في السوق لضمان بيعها & r \\
\hline$\cdot,+r \leq$ & $\cdot, T Y 1$ & التعامل مع شكاوى العملاء يتتج عنه تكاليف تفوق احيانا تكلفة المنتج & $r \leq$ \\
\hline
\end{tabular}

المجلد الحادي والاربعون الجزء الثاني، مارس ^| • ب 
ثبات فقرات الاستبانة Reliability ما ثبات أداة الدراسـة فيعني التأكد من أن الإجابـة ستكون واحدة تقريباً لو نكرر تطبيقها على الأشخاص ذاتهم في أوقات (العساف،

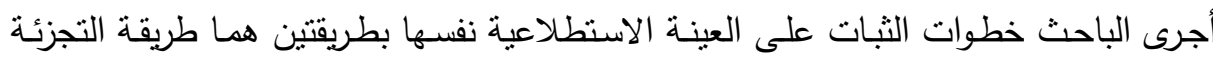
النصفية ومعامل ألفا كرونباخ.

أولاً: طريقة التجزئة النصفية: Coefficient Half-Split: : تمعله إيجاد معامل ارتباط بيرسون

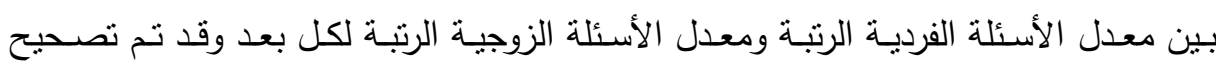
معاملات الارتباط باستخدام معامل ارتباط سبيرمان براون للتصحيح حسب المعادلة التالية :

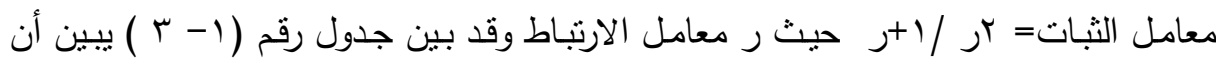
هناك معامل ثبات كبير نسبيا لفقرات الاستب هان مما يطمئن الباحث على استخدام الاستبانه بكل طمأنينة.

جدول رقم(ץ): معامل الثبات ( طريقة التجزئة النصفية)

\begin{tabular}{|c|c|c|c|}
\hline الاحتمالية & معامل الارتباط & الارتباط & \\
\hline$\cdot, \ldots$ & $\cdot, \wedge 94$ & $\cdot, \vee \backslash \backslash \leqslant)$ & مدى أهمية قياس تكاليف الجودة. \\
\hline$\cdot, \ldots$ & $\cdot, \wedge 07 \varepsilon$ & $\cdot, V \cdot T Y$ & اههية الرقابة على تكاليف الجودة في تحسين الاداء المالى \\
\hline
\end{tabular}

ثانياً: طريقة ألفا كرونياخ :Alpha s'Cronbach : استخدم الباحث طريقة ألفا كرونباخ لقياس ثبات الاستبانه كطريقة ثانية لقياس الثبات وقد يبين جدول رقم (1-ع) أن معاملات الثبات مرتفعة مما يطمئن الباحث على استخدام الاستبانة بكل طمأنينة.

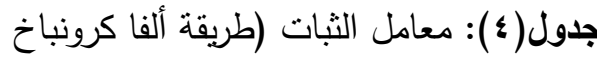

\begin{tabular}{|c|c|c|}
\hline كرونباخ & الفقرات & 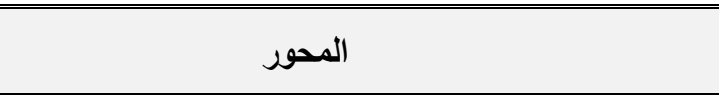 \\
\hline$\cdot, \wedge \uparrow \cdot \mathrm{V}$ & $r \varepsilon$ & مدى أهمية قياس تكاليف الجودة. \\
\hline$\cdot, \wedge 0 \leqslant Y$ & $r \varepsilon$ & اهمية الرقابة على تكاليف الجودة فى تحسين الاداء المالى . \\
\hline
\end{tabular}


المعالجـات الإحصـائية: لتحقيق أهداف الدراسـة وتحليل البيانات التي تم تجميعها، فقد تم

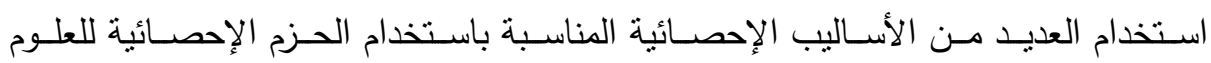

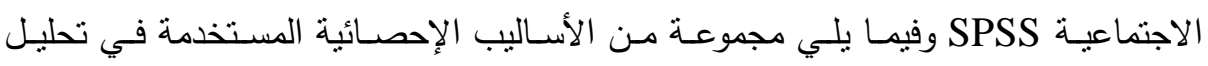

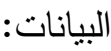

(1) تم حساب التكرارات والنسب المئوية للتعرف على الصفات الثخصية لمفردات الدراسة

وتحديد استجابات أفرادها تجاه عبارات المحاور الرئيسة التي تتضنهاتها أداة الدراسة (Y) المتوسط الحسابي Mean وذلك لمعرفة مدى ارتفاع أو انخفاض استجابات أفراد الدراسة

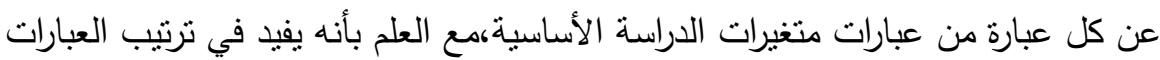

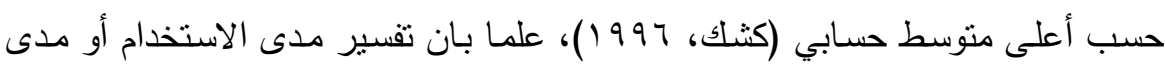
الموافقة على العبارة

(r) تم استخدام الانحراف المعياري) Deviation Standard) للتعرف على مدى انحراف استجابات أفراد الدراسة لكل عبارة من عبارات متغيرات الدراسة ولكل محور من المحاور

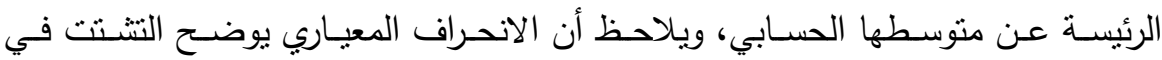

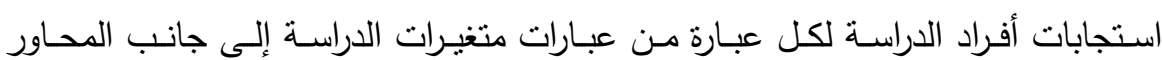
الرئيسية، فكلما اقتربت قيمته من الصفر كلما نركزت الاستجابات وانخفض تشتتها بين

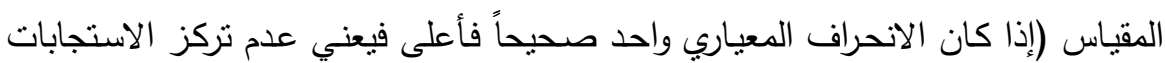
وتشتنها. ( ) اختبار ألفا كرونباخ لمعرفة ثنات فقرات الاستبانة (0) معامل ارتباط بيرسون لقياس صدق الفقرات . معادلة سبيرمان براون للنبات

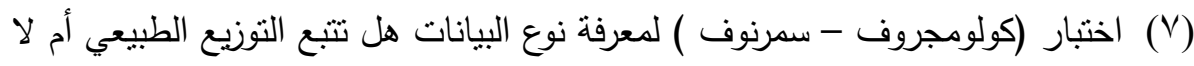
(^) لمتوسط عينة واحدة test T sample One لمعرفة الفرق بين منوسط الفقرة والمتوسط الحيادي 
اختبار التوزيع الطبيعي (اختبار كولمجروف): تم استخدام اختبار كولمجروف - سمرنوف

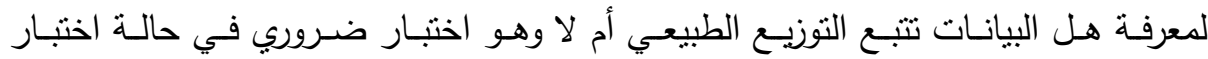
الفرضيات لأن معظم الاختبارات المعلمية نتشترط أن يكون نوزيع البيانات طبيعياً.

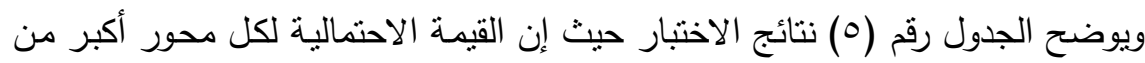

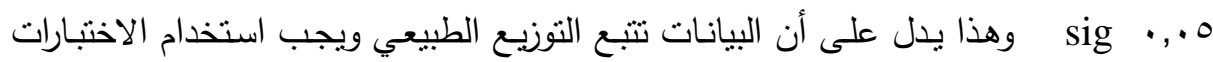

المعلمية.

جدول رقم(•): اختبار التوزيع الطبيعى ( 1-Sample Kolmogorov-Smirnov )

\begin{tabular}{|c|c|c|c|}
\hline الاحتمالية & 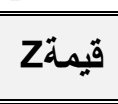 & الفقرات & \\
\hline$\cdot, 99 Y$ & $\cdot, \leqslant \Psi \leqslant$ & T乏 & مدى أهمية قياس تكاليف الجودة. \\
\hline$\cdot, Y M I$ & $1, \cdot T \leq$ & T纟 & دور تكاليف الجودة في تحسين الاداء المالى \\
\hline$\cdot, \varepsilon \mu \uparrow$ & $\cdot$, AVO & 71 & المجموع \\
\hline
\end{tabular}

تحليل فقرات محاور الدراسة:

الجزء الأول: بيانات عامة

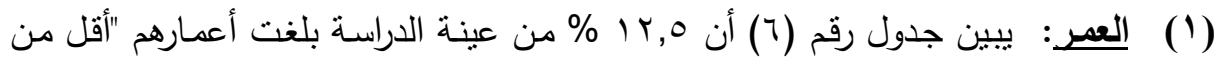

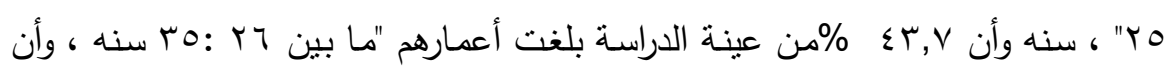

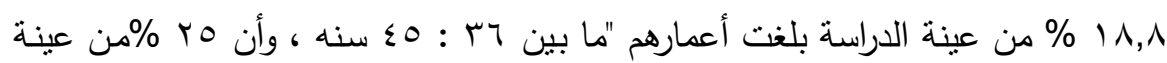

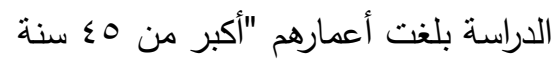

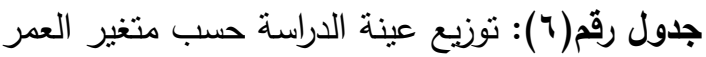

\begin{tabular}{|c|c|c|}
\hline النسبة المئوية & التكرار & العمر \\
\hline $1 Y, 0$ & $\varepsilon$ & اقل من O T سنة \\
\hline$\varepsilon r, V$ & $T \varepsilon$ & من ج Y الى هب سنة \\
\hline$\overline{1 \Lambda, \Lambda}$ & 7 & من بس الى 0؛ سنة \\
\hline ro & $\Lambda$ & اكبر من ه ؛ سنة \\
\hline $1 \ldots$ & TY & المحموع \\
\hline
\end{tabular}




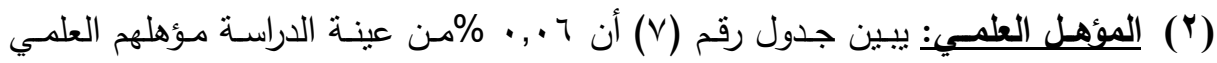

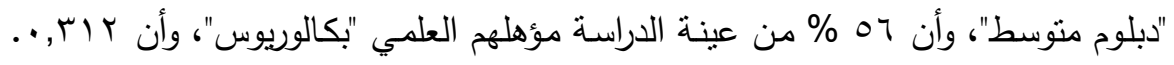

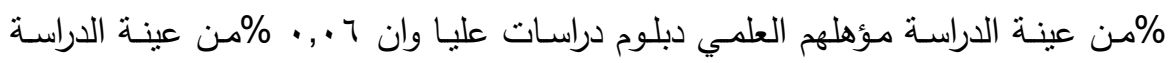

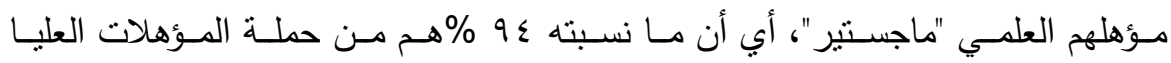

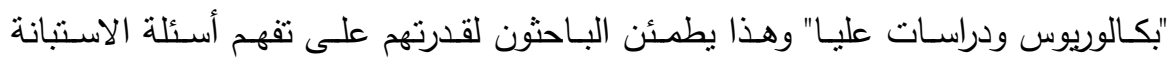

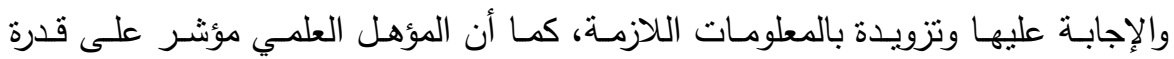
وكفاءة المبحوثين

\begin{tabular}{|c|c|c|}
\hline النسبة المئوية & التكرار & الموهل العلمى \\
\hline$\cdot, \cdot 7$ & $\bar{T}$ & دبلوم منتوسط \\
\hline., 07 & 11 & بكالوريوس \\
\hline$\cdot, \mu \mid r$ & 1. & دبلومة دراسات علبا \\
\hline$\cdot, \cdot 7$ & $r$ & ماجيستير \\
\hline $1 \cdots$ & rr & المجموع \\
\hline
\end{tabular}

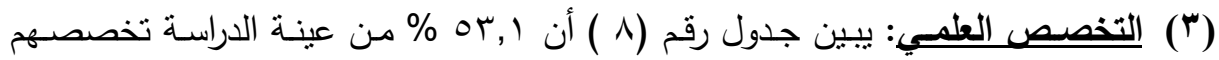

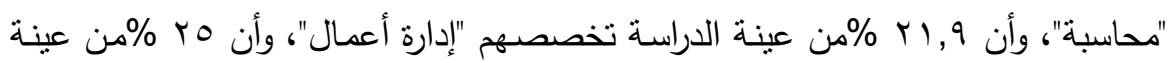

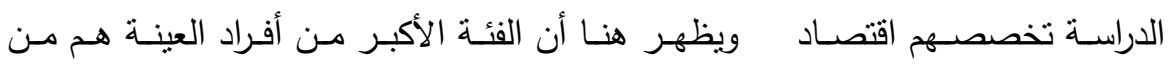

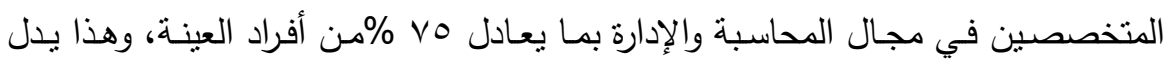
على فهم أفضل لأسئلة الاستبانه وإجابات أدق.

\begin{tabular}{|c|c|c|}
\hline النسبة المئوية & التكرار & التخصص العلمى \\
\hline Or,1 & $1 \mathrm{IV}$ & قسم محاسبة \\
\hline YI, & V & قسم ادارة اعمال \\
\hline TO & $\Lambda$ & قسم اقتصـاد \\
\hline $1 \ldots$ & Tr & الاجمالى \\
\hline
\end{tabular}

(؛ ) سنوات الخبرة: يبين جدول رقم (9) أن أكبر فئة من من أفراد العينة هي مدن نزيد

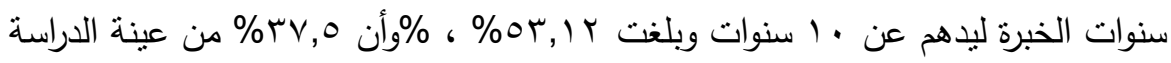
تراوحت سنوات الخبرة ما بين ا-9 سنوات ، مما يعني أن ما يعادل 9 \% من أفراد العينة 
تزيد سـوات الخبرة مـا بين ؟- ـ ،، وهذا يدل على أن مستوى الخبرة لدى أفراد العينـة مناسب مما يعني فهم أكبر لأسئلة الاستبانة ومدلولاتها. جدول رقم(9) : توزيع عينة الدراسة حسب منغير سنوات الخبرة

\begin{tabular}{|c|c|c|}
\hline النسبة المئويـة & التكرار & سنوات الخبرة \\
\hline$r V, 0$ & IT & من ا : 0 سنوات \\
\hline., .9 & $r$ & من 7 : · 1 سنوات \\
\hline Or,IY & IV & اكثر من · ا سنوات \\
\hline $1 \ldots$ & Tr & الاجمالي \\
\hline
\end{tabular}

الفرض الرئيسى: لا يوجد دور ذو دلالة معنوية للتكاليف البيئية فى تحسين الاداء المالى للشركات الصناعية وزيادة القدرة التنافسية لهذه الشركات.

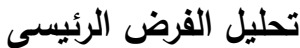
أولاً: لا يوجـــ دور ذو دلالــة معنويـة لتكـاليف الوقايـة فـى تحسـين الاداء المـالى للثـركات الصناعية وزيادة القدرة التتافسية لهذه الثركات تم استخدام اختبار t للعينة الواحدة والنتائج مبينة في جدول رقم (1- (1 ) والذي يبين آراء أفراد عينـة الدراسـة في فقرات المحور الفرعي الأول ( تكاليف الوقايـة) وتبين النتائج أن

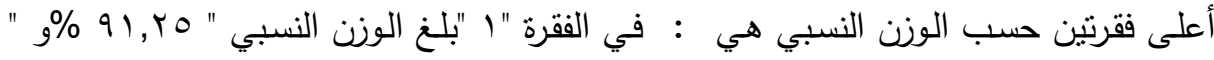

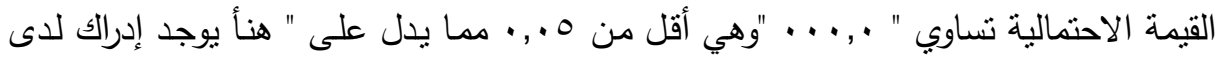

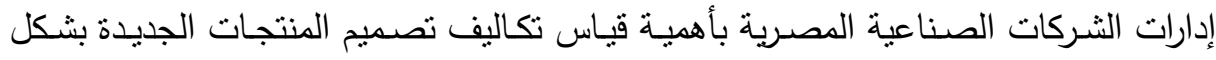

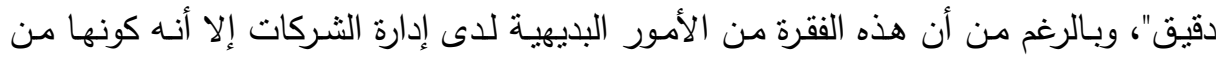

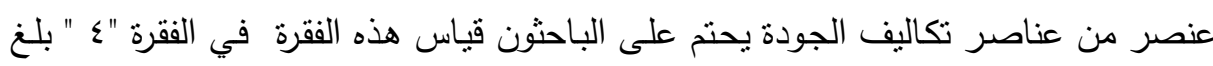

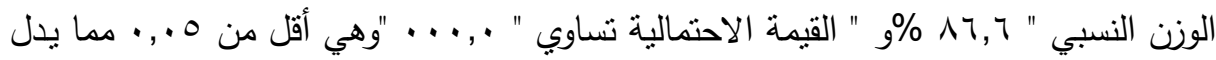

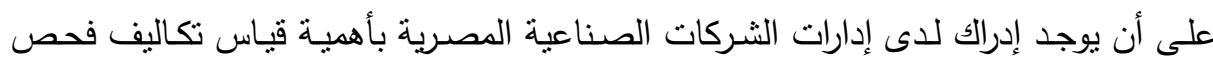

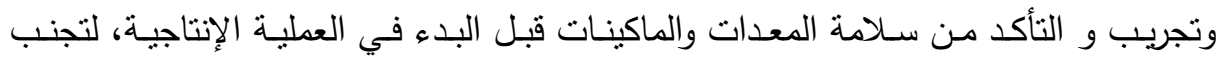

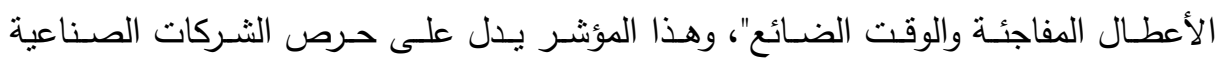

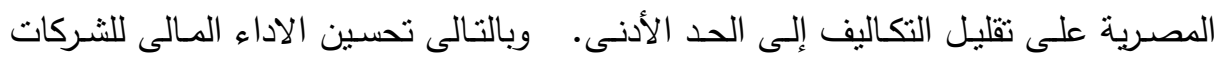
الصناعية كما تبين النتائج أن أقل فقرتين حسب الوزن النسبي هي في الفقرة م " "بلغ الوزن الودئ 506

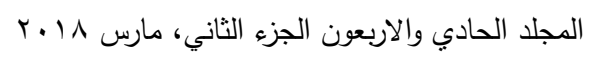




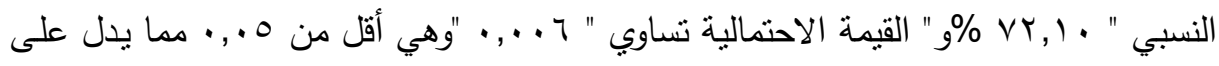

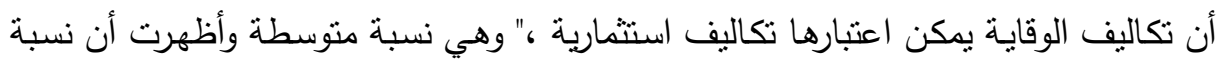

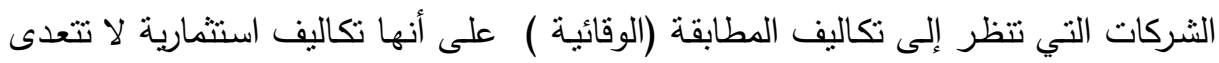

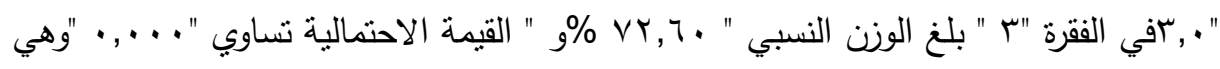
أقل من 0 ., • مما يدل على انه يوجد إدراك لدى إدارات الشركات الصناعية المصرية بأهمية

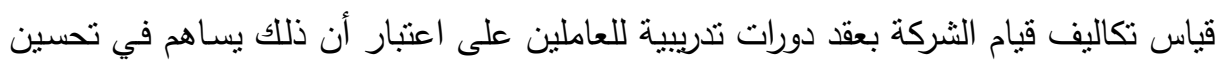

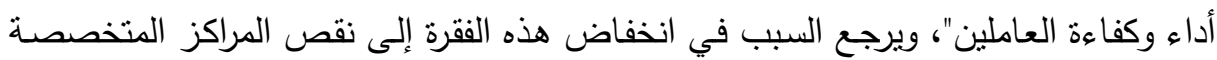

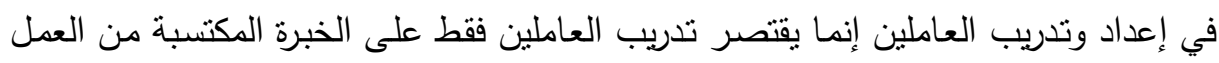

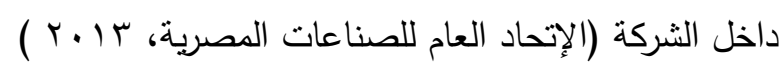

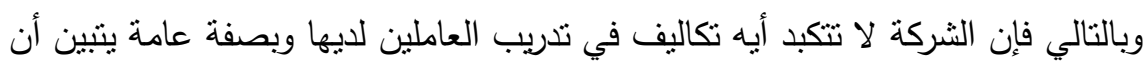

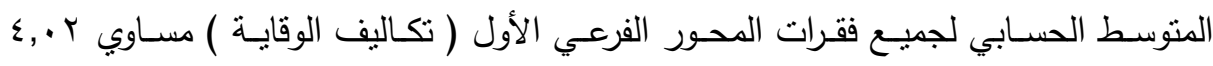

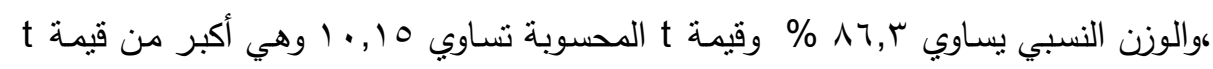

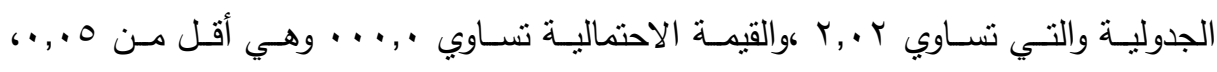

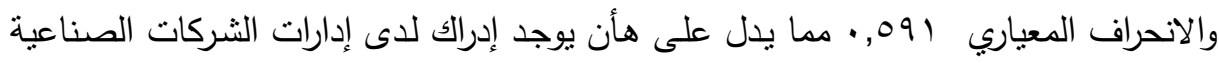

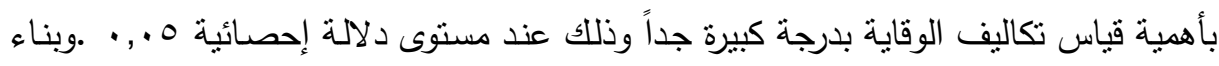

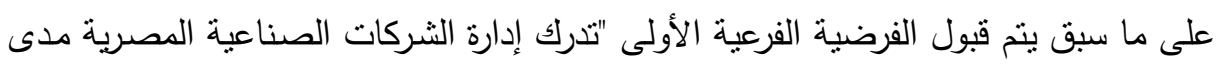

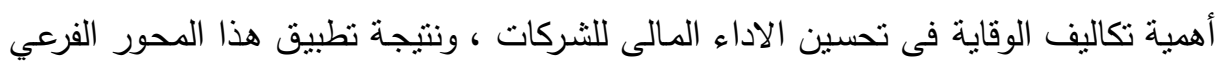

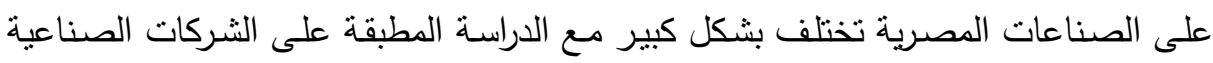
المصرية حيث بينت أن المتوسط الحسابي لإدراك الشركات بتكاليف الوقاية ب م ,ـ 
مجلة العلوم البيئية

معهز الدراسات والبحوث البيئية - جامعة عين شمس لهن

جدول (• (1): تحليل فقرات المحور الاول تكاليف الوقاية

\begin{tabular}{|c|c|c|c|c|c|c|}
\hline الاختبارية & قيمة t & الوزن النسبي & المعيارى & المتوسط & الفقرة & م \\
\hline$\cdot, \cdots$ & $1 \cdot, 0 r$ & $91, r$ & $\cdot, \wedge \varepsilon$. & $\{, 07$ & الجديدة بشكل دقيق تكاليف تصميم المنتجـات & 1 \\
\hline$\cdot, \cdots r$ & 9, ro $^{\circ}$ & $\Lambda T, M_{1}$ & $\cdot, 7 V V$ & $\{, 17$ & 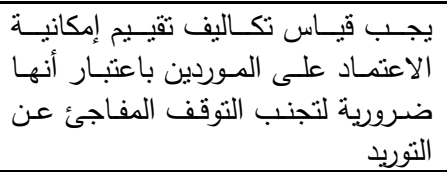 & $r$ \\
\hline$\cdot, \ldots r$ & זד,ז & $V Y, T$ & $1, r$ & זד, זי & 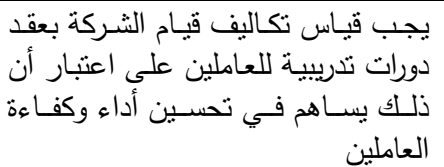 & $r$ \\
\hline$\cdot, \cdots$ & Q,rT & $\wedge_{\top}, \uparrow$ & $\cdot, 0 \leqslant r$ & $\varepsilon, Y_{O}$ & 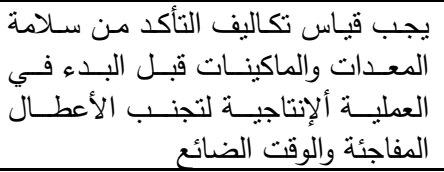 & $\varepsilon$ \\
\hline$\cdot, \cdots$ & דוז,7 & NT,r & $\cdot, 97 \varepsilon$ & $\leq, 10$ & 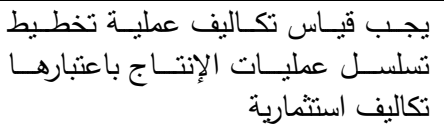 & 0 \\
\hline$\cdot, \cdots$ & $\varepsilon, r r$ & Vq,r & $\cdot, 07 \leqslant$ & $r, 70$ & يجب قياس تكاليف التخطيط والتكاليف & 7 \\
\hline$\cdot, \cdots r$ & אז, ד & $\Delta r, \varepsilon \varepsilon$ & •, 974 & $\{, Y)$ & 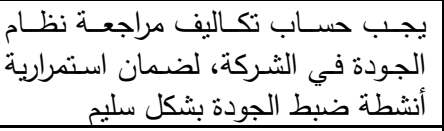 & V \\
\hline$\cdot, \cdots 7$ & $\{, Y)$ & $V Y, 1$ & $\cdot, \wedge \circ \leqslant$ & $r, 74$ & استثتمارية الوقايـة يمكن اعتبارهـا تكاليف & $\Lambda$ \\
\hline$\cdot, \cdots$ & $1 ., 10$ & $\wedge \uparrow, r$ & $\cdot, 091$ & $\varepsilon, \cdot r$ & المجموع & \\
\hline
\end{tabular}

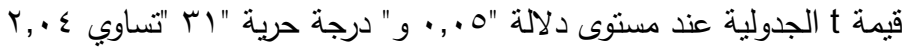
ثانيا: لا يوجد دور ذو دلالة معنوبة لتكاليف التقييم فى تحسين الاداء المالى للثركات الصناعية وزيادة القدرة النتافسية لهذه الثركات

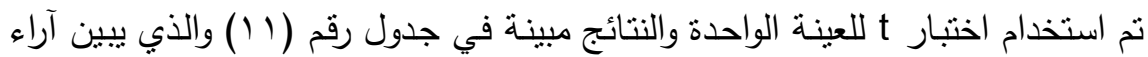
أفراد عينة الدراسة في فقرات المحور الفرعي الثاني ( تكاليف التقييم ) وتبين النتائج أن أعلى

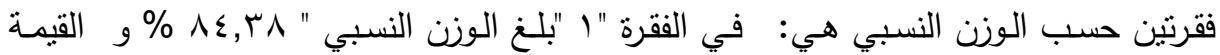


الاحتمالية تساوي " ...., • "وهي أقل من ه., • مدا يدل على هنأ يوجد إدراك لدى إدارات

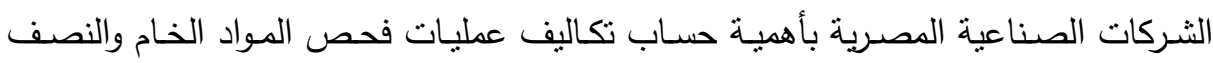

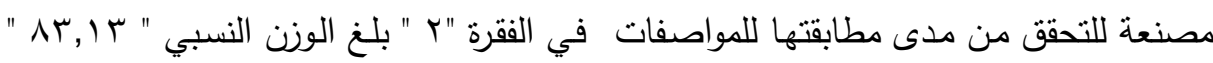

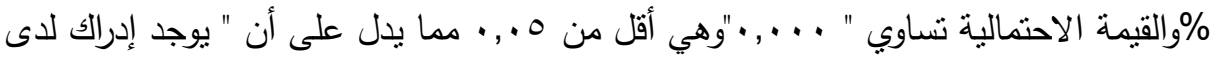

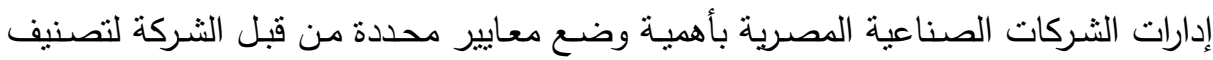

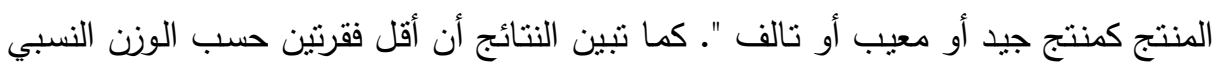

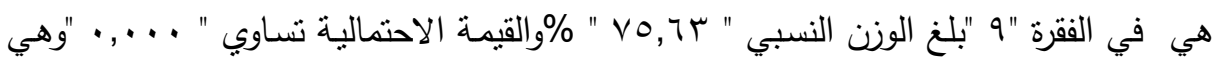

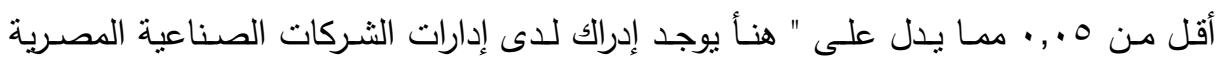

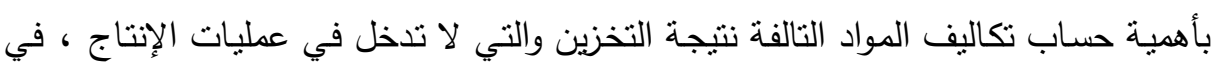

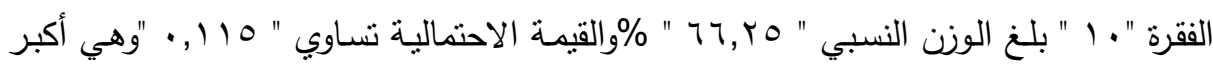

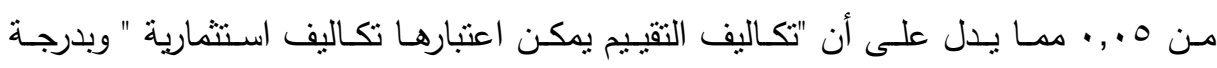
متوسطة، ويرى الباحثون أن السبب في انخفاض هذا العنصر ناتج عن احتواء تكاليف الثقييم على تكاليف رأسمالية وتكاليف أخرى تشغيلية، وهذا ما أثنار تباين الآراء حول مدى اعتبارها

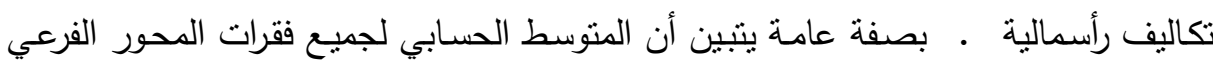

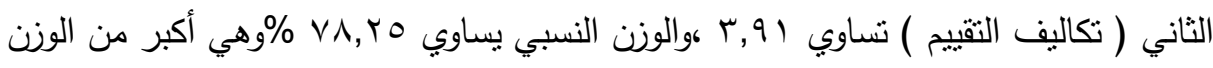

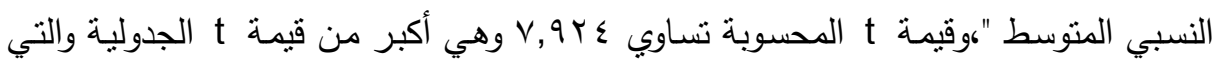

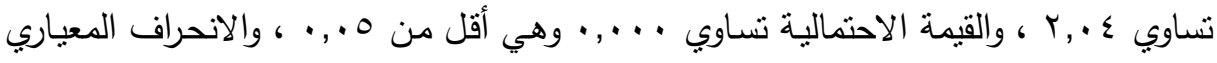

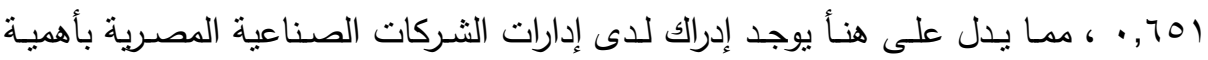

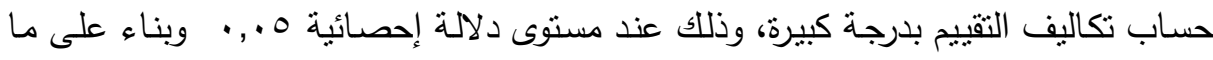

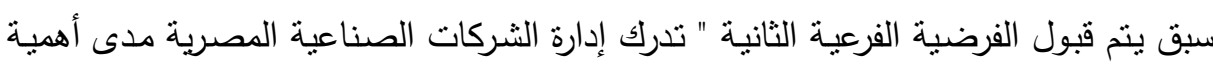
تكاليف التقييم ونتيجة نطبيق هذا المحور الفرعي على الثركات الصناعية. 
مجلة العلوم البيئية

معهز الدراسات والبحوث البيئية - جامعة عين شمس لهن

جدول(1)

\begin{tabular}{|c|c|c|c|c|c|c|}
\hline الاحتمالية & قيمة t & النسبي & الانحراف & المستوسط & الفقرة & م \\
\hline$\cdot, \cdots$ & $9,1 \wedge \varepsilon$ & $\wedge \varepsilon, \Gamma \wedge$ & $\cdot, \times 01$ & $\varepsilon, Y Y$ & 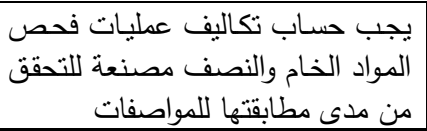 & 1 \\
\hline$\cdot, \cdots$ & $\mathrm{V}, \varepsilon$ & & $\cdot, \wedge \wedge \leq$ & $\{, 17$ & 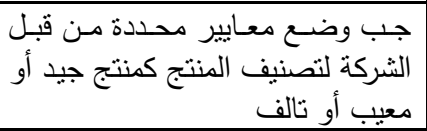 & $r$ \\
\hline$\cdot, \cdots$ & $7, \Sigma$ & $\Lambda \cdot, \ldots$ & $\cdot, \wedge \wedge$. & $\varepsilon, \cdots$ & 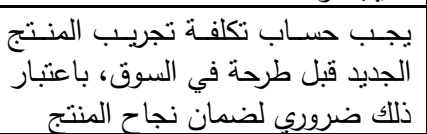 & $r$ \\
\hline$\cdot, \cdots$ & $\varepsilon, r T$ & $V Y, Y_{O}$ & $1, \cdot 7$. & $r, \Lambda)$ & 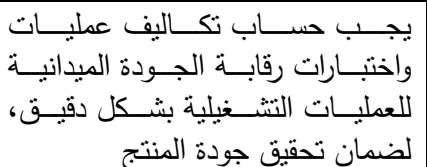 & $\varepsilon$ \\
\hline$\cdot, \cdots$ & גזr,ד & $\Lambda, Y_{0}$ & $\cdot, 9 \leq \wedge$ & $\varepsilon, \cdot 7$ & 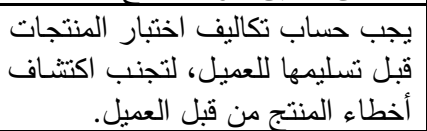 & 0 \\
\hline$\cdot, \cdots$ & $T, I Y Y$ & $\lambda r, 0$ & $1, \cdot \varepsilon$. & $\varepsilon, 1 T$ & 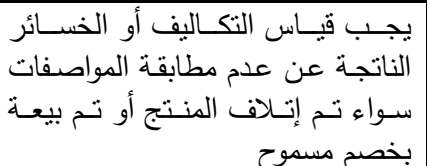 & \\
\hline$\cdot, \cdots$ & $\{, \vee \backslash 1)$ & $V V, 0$ & $1, \cdot \varepsilon$ & $\Gamma, \wedge \wedge$ & يجب أدوات ومعدات الفحضذ في الاعتبـار تكـاليف & $\mathrm{V}$ \\
\hline$\cdot, \cdots$ & $\varepsilon, 790$ & Vo,T & $\cdot, 9 \leq 1$ & 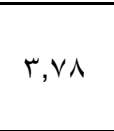 & 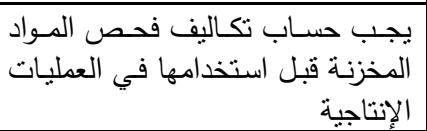 & $\Lambda$ \\
\hline$\cdot, \cdots$ & $\varepsilon, I T r$ & Vo,T & $1, \cdot V$ & $\Gamma, \vee \wedge$ & 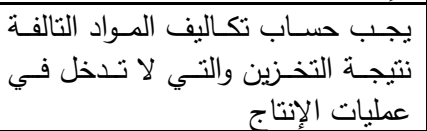 & 9 \\
\hline$\cdot, 110$ & I,TYו & $7 T, Y_{0}$ & $1, .9$ & ו & تكاليف الوقاية يمكن اعتبارها تكاليف & 1. \\
\hline$\cdot, \ldots$ & $V, 9 Y \leq$ & $V \wedge, Y_{0}$ &., 701 & $r, q 1$ & المجموع & \\
\hline
\end{tabular}

قيمة t الجدولية عند مستوى دلالة "ه ., · و و" درجة حرية " اب "تشاوي ع •., 
ثالثا: لا يوجد دور ذو دلالة معنوية لتكاليف الفشل الداخلى فى تحسين الاداء المالى للشركات

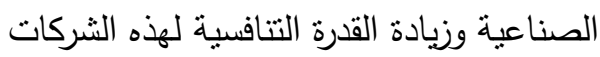

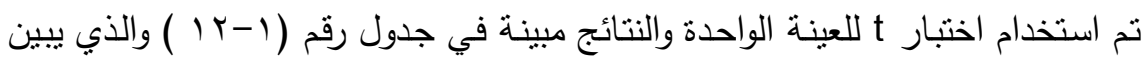
آراء أفراد عينـة الدراسـة في فقرات المحور الفرعي الثالث ( تكاليف الفشل الداخلي ) وتبين

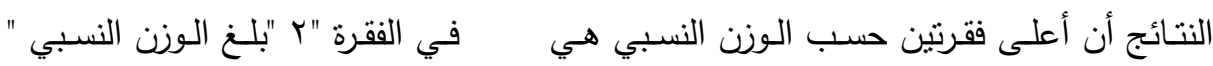

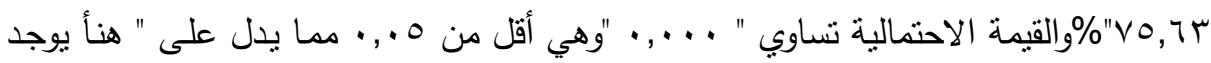

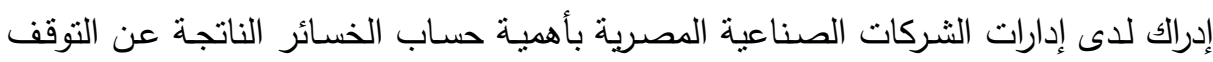

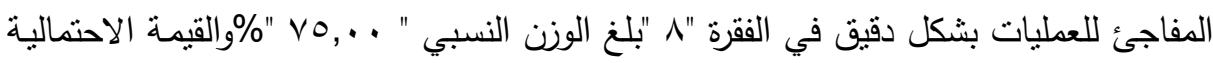

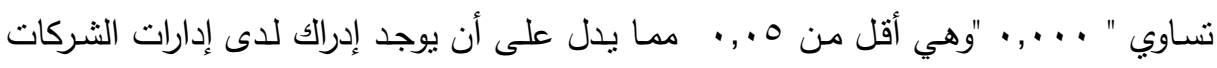

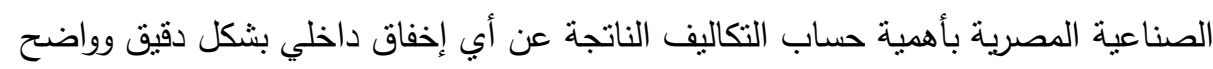

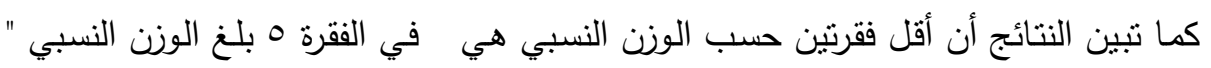

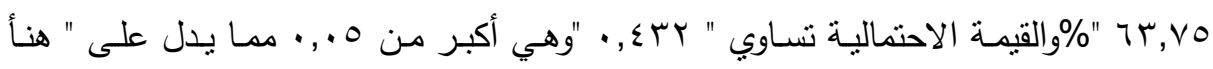

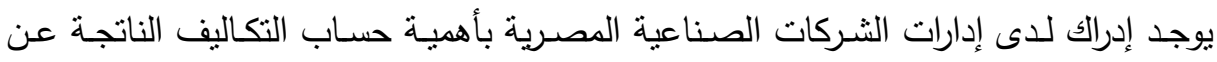

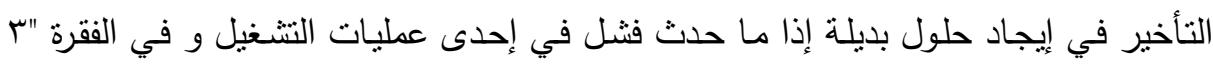

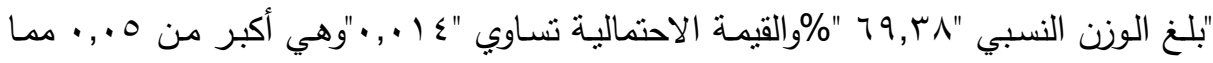

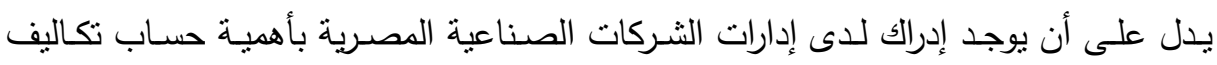

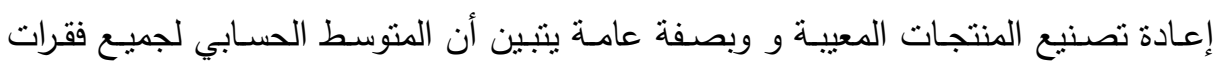

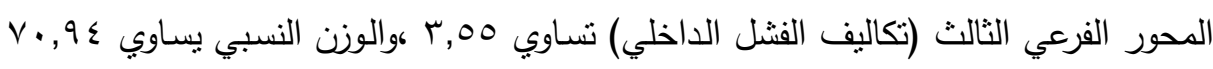

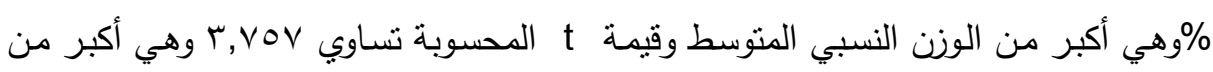

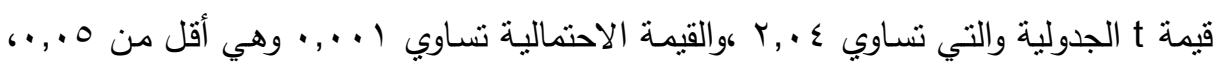

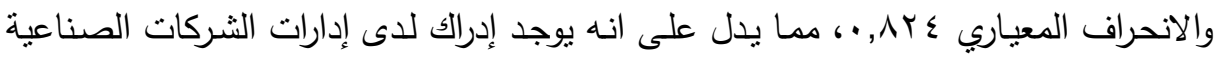

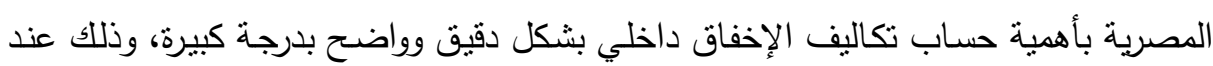

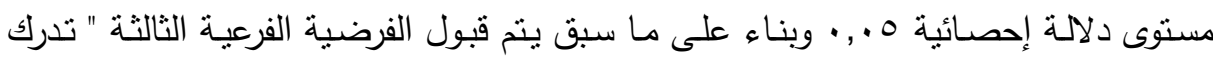


إدارة الثركات الصناعية المصرية مدى أهمية تكاليف الفشل الداخلي." فى تحسين الاداء

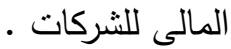
جدول(r ا ): تحليل فقرات المحور الثالث تكاليف الفشل الداخلى

\begin{tabular}{|c|c|c|c|c|c|c|}
\hline الاحمالية & قيمة t & النسبي & الانحريارى & الحسابي & الفقرة & r \\
\hline$\cdot, \cdots \varepsilon$ & $r, 1 q^{\prime}$ & $\vee \backslash, \wedge \wedge$ & $1, \cdot V r$ & $r, 09$ & سجب تقدير المواد الخام بشكل دقيق التوات واضح. الناتجة عن & 1 \\
\hline$\cdot, \cdots$ & $\varepsilon, \Gamma \wedge$ & Vo, T & $1, \ldots 1$ & $V, r V$ & 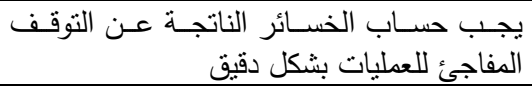 & $r$ \\
\hline$\cdot, \cdot 1 \leqslant$ & $r, T \backslash 1$ & $\neg 9, \Gamma \wedge$ & $1, .17$ & $r, \Sigma V$ & 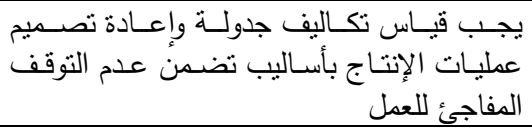 & $r$ \\
\hline$\cdot, \cdot r \leq$ & $r, r v$. & $v_{1}, r_{0}$ & $1, r 01$ & r,0 & 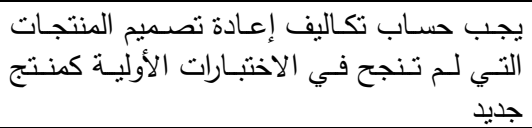 & $\varepsilon$ \\
\hline r, & $\cdot, \vee 07$ & ד, & • שז,1 & $r, 19$ & ليجب حسيبة حساب تكـاليف اعـادة تصنيع المنتجـات & 0 \\
\hline$\cdot, 1>0$ & $1, r_{0}$ & $\checkmark \backslash, \wedge \wedge$ & $1, r r \varepsilon$ & $r, r \varepsilon$ & 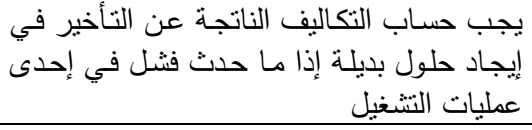 & \\
\hline$\cdot, \cdots$ & $r, \wedge ৭ \vee$ & $\vee r, V_{0}$ & $\cdot, 991$ & r,79 & 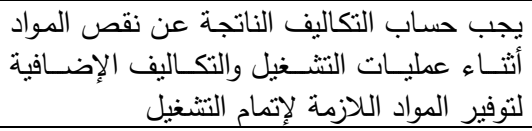 & V \\
\hline$\cdot, \cdots$ & ז,T & $v_{0}, \ldots$ & $\cdot, 917$ & r,vo & يجب حساب التكاليف الناتجة عن أي إخفاق & $\Lambda$ \\
\hline,$\ldots 1$ & $r, v \circ V$ & $V \cdot, q \leq$ & $\cdot, \wedge r \leq$ & $r, 00$ & المجموع & \\
\hline
\end{tabular}

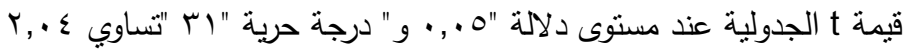

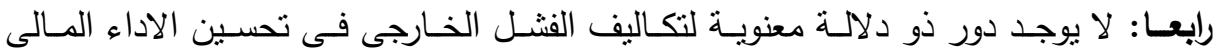
اللشركات الصناعية وزيادة القدرة التتافسية لهذه الثركات تم استخدام اختبار t للعينة الواحدة والنتائج مبينة في جدول رقم (1-r إ) والذي يبين آراء أفراد عينـة الدراسـة في فقرات المحور الفرعي الرابع ( تكاليف الفثـل الخـارجي) وتبين

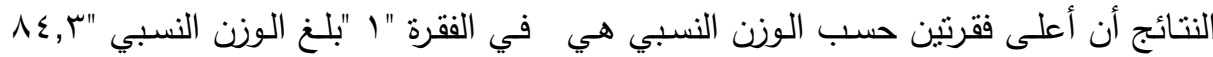

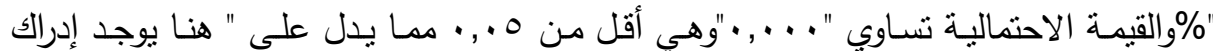


لادى إدارات الشركات الصناعية المصرية بأهمية تقدير الخسائر الناتجـة عن فقدان السمعة

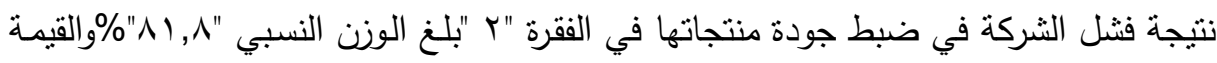

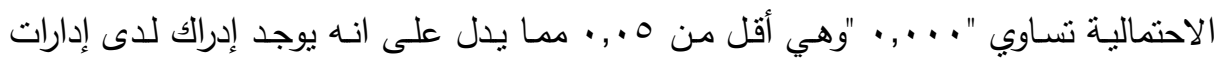

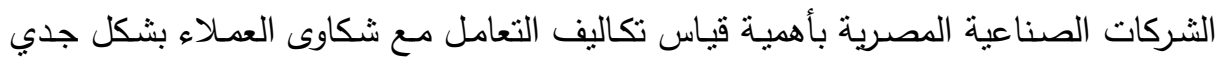

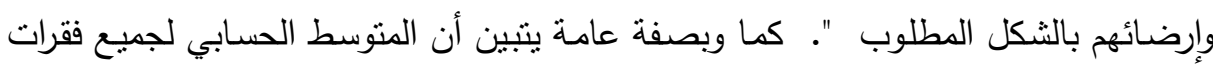

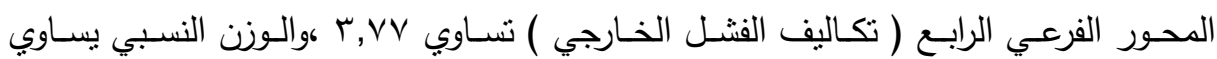

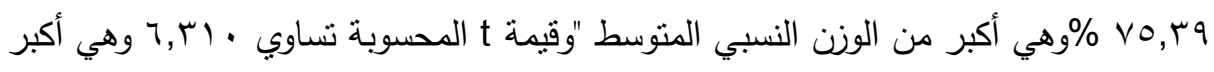

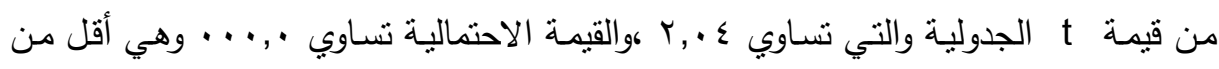

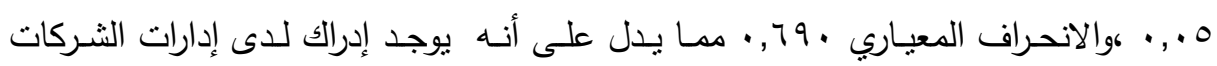

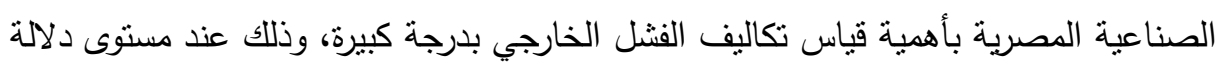

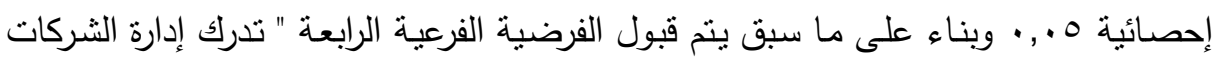
الصناعية المصرية ددى أهمية تكاليف الفشل الخارجي فى تخفيض التكاليف وتحسين الاداء

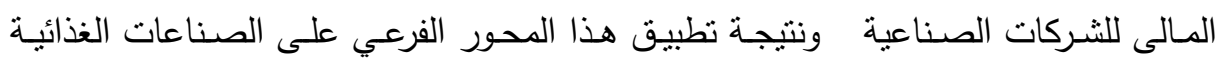

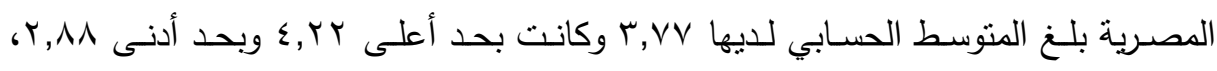

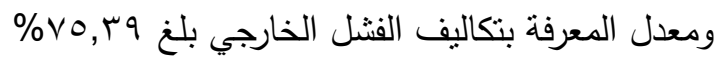


مجلة العلوم البيئية

معهز الدراسات والبحوث البيئية - جامعة عين شمس لهن

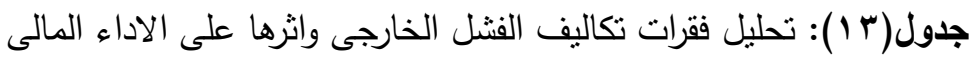

\begin{tabular}{|c|c|c|c|c|c|c|}
\hline الاحتمالية & قيمة t & 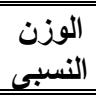 & الانحراف & المتوبط & الفقرة & p \\
\hline$\cdot, \cdots$ & $v, \cdot v_{1}$ & $\Lambda \varepsilon, r$ & 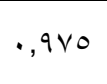 & $\varepsilon, Y$, & 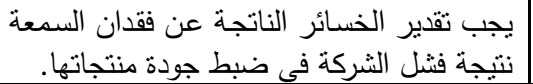 & 1 \\
\hline$\cdot, \cdots$ & $\vee, 0 \wedge$ & $\wedge 1, \wedge$ & $\cdot, \wedge \backslash \wedge$ & $\varepsilon, \cdot 9$ & 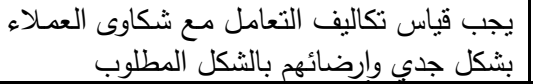 & $r$ \\
\hline$\cdot, \cdots$ & $\varepsilon, I M r$ & Vo,T & $1, \cdot v \cdot$ & $r, \vee \wedge$ & 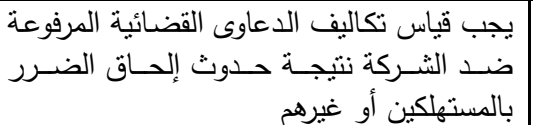 & $r$ \\
\hline$\cdot, \cdots$ & $\varepsilon, \Gamma \wedge \uparrow$ & $v_{0, T}$ & $1, \ldots 1$ & $r, \vee \wedge$ & 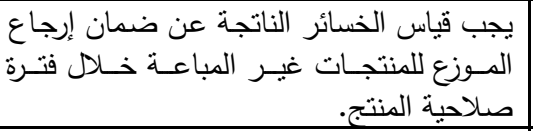 & $\varepsilon$ \\
\hline$\cdot, \cdots$ & $\varepsilon, \leqslant 17$ & $\vee \neg, \wedge$ & $1, \cdot 11$ & $\Gamma, \wedge \varepsilon$ & المعيبة والتالفة التى بنت اكتشافيف أو خسائر تبديل المنتجات & 0 \\
\hline$\cdots$ & $0,1 \cdot 0$ & $\vee \wedge, \vee$ & $\cdot, 91 \leq$ & r, १ะ & 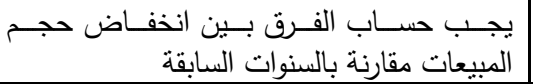 & \\
\hline$\cdot, \cdots r$ & $r, \varepsilon .1$ & $V Y, O$ & $1, \cdot \varepsilon$. & זד, ז & 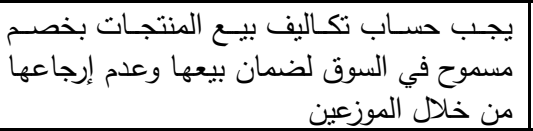 & $\mathrm{v}$ \\
\hline . oro & ع & $O V, 0$ & $1,1 \ldots$ & $r, \wedge \wedge$ & 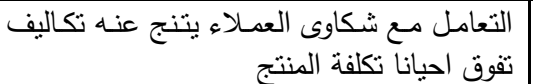 & $\Lambda$ \\
\hline$\cdot, \cdots$ & $7, \pi$. & $v 0, r q$ & $\cdot, 79$. & $r, V V$ & |المجموع & \\
\hline
\end{tabular}

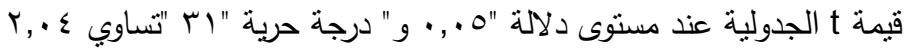

\section{المتأئ}

$$
\text { تتلخص نتائج الدراسة فى الاتى: }
$$

(1) أظهرت الدراسة أنه يوجد إدراك لدى إدارات الثركات الصناعية في مدى أهمية قياس

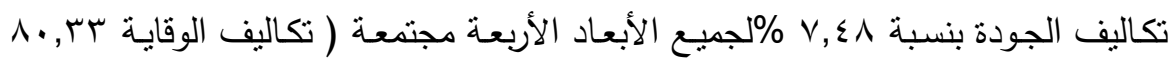

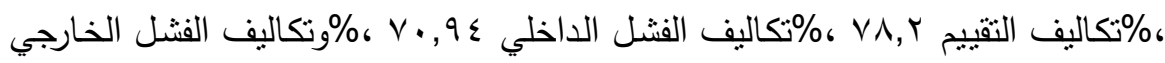




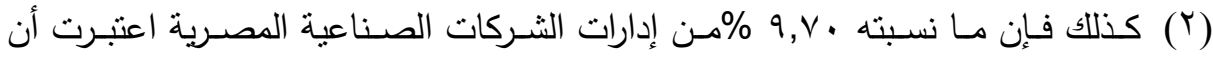

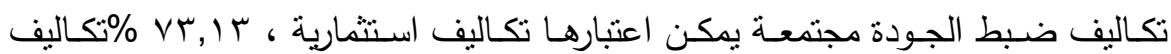
الوقاية ، 0Y \% \%تكاليف التقييم

بـالرغم من محدوديـة جودة بعض المنتجـات الغذائيـة المصنوعة محلياً، إلا أنـه تطبق

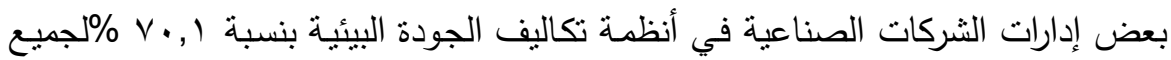

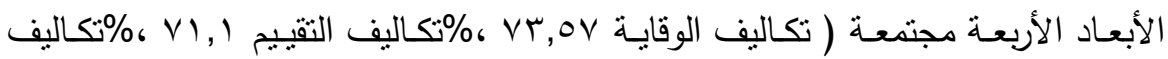

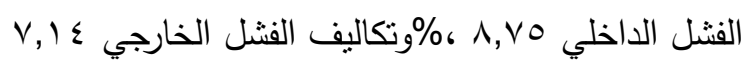

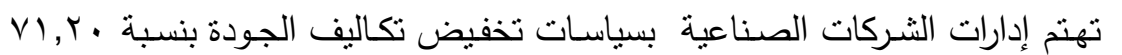

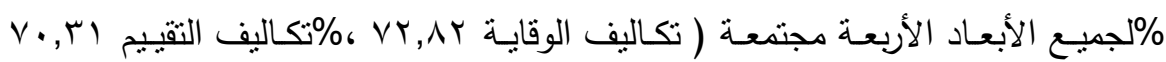

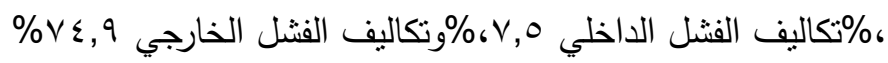
إن وجـود فـروق ذات دلالــة إحصـائية لـدى إجابـات المبحوثين تعـزى إلىى التخصـص العلمي، وعدم وجود فروق تعزى إلى سنوات الخبرة يدل على دور التخصص العلمي في لعي

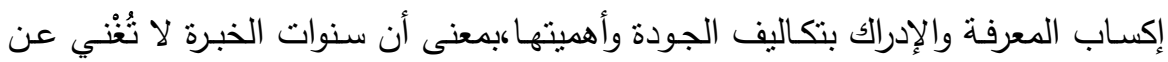

$$
\text { التخصص العلمي في إكساب المعرفة. }
$$

\section{اللجمصياهث}

يقترح الباحثون زيادة رفع مستوى إدراك إدارات الثـركات الصناعبة المصرية لأهمية

قياس ورقابة تكاليف الجودة، وذلك من خلال:

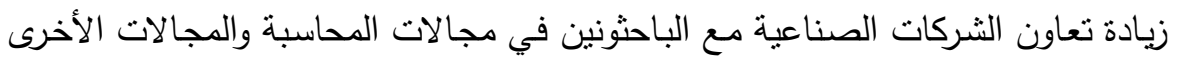

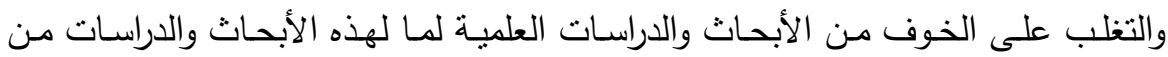
منافع تعود على الثركات الصناعية بشكل خاص وعلى المجتمع ككل بشكل عام الام

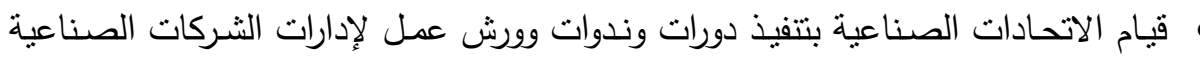

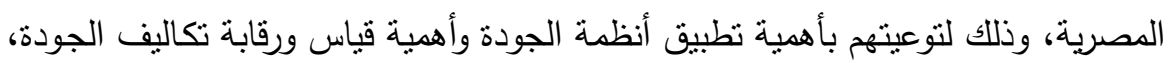
والمنافع المترتبة على ذلك لكل من الثركة بشكل خاص والمجتمع بشكل عام . 
• ضـرورة قيام النقابـات والهيئات الخاصـة بمجتمع رجـال الأعمـال بتوعيـة إدارات الثـركات

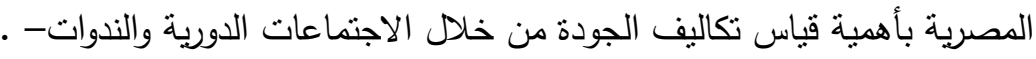

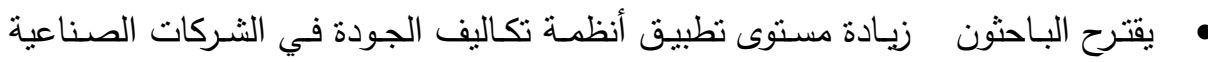
المصرية، وذلك من خلال إعداد دورات تدريبية للعاملين فى الوحدات الحسابية في لئي الثركات الصناعية المصرية لتدريبهم على كيفية التعامل مع تكاليف الجودة، وزيادة القدرة على تصنيف وتبويب تكاليف الجودة وإعداد التقارير للإدارة عن هذه التكاليف بالثنكل

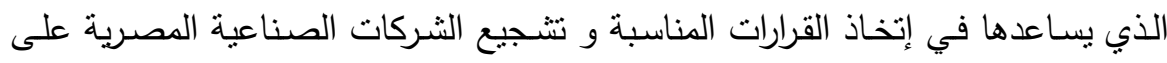
التعامل مع مؤسسات المواصفات والمقاييس المحلية بشكل خاص ومؤسسات المواصفات والمقاييس العالمية .

يقترح الباحثون ضرورة إهتمام الثركات الصناعية المصرية بسياسات تخفيض تكاليف

الجودة، وذلك من خلال

زيادة إستثمار الثركات الصناعية المصرية في تكاليف وقاية وتقييم الجودة بشكل مناسب، وذلك لتتاسب العلاقة العكسية بين كل من تكاليف المطابقة الوقاية والثقيبم وتكاليف عدم المطابقة الفشل الداخلي والخارجي • يقترح الباحثون ضرورة وضع الثركات الصناعية المصرية للخطط والمعايير والسياسات التـي تضـمن حسن سـير العمليـات الإنتاجيـة، وضـرورة الإلنزام بهذه الخطط والمعـايير والسياسات وذلك لتقليل مشكلات عمليات الإنتاج و عيوب التصنيع التي تؤدي إلى زيادة تكاليف الفنشل الداخلي، والفشل الخارجي إلى الحد الأدنى.

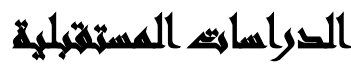

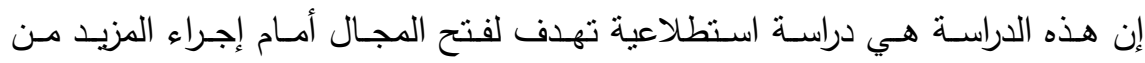

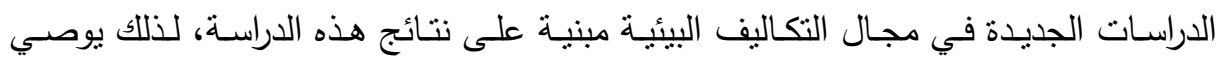
الباحثون بإجراء الدراسات التالية: 
(1) أثز إعداد الموازنات التشغيلية على تخفيض تكاليف الجودةالبيئية (r) أثر اسـتخدام (نمـاذج تكاليف الجودة المختلفة) على تخفيض التهـاليف في الثـركات الصناعية

\section{sall}

أحمد محمد حامد حجاج(| (1 ـ ب ) محاسبة التكاليف مدخل إداري، الجزء الثاني، الرياض، دار المريخ

أحمد فؤاد راثند، عبد المنعم محمد(9 . . ب ) أساسيات التقييس وجودة الإنتاج، دار الجامعات المصرية

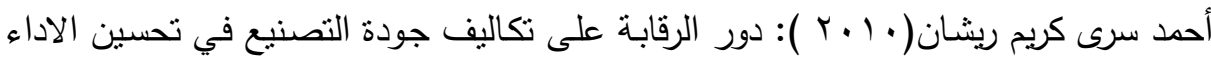

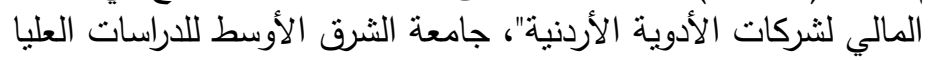

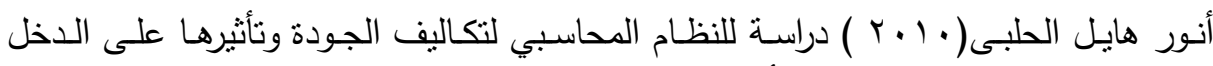
والعائد الربحي"، الأكاديمية العربية البريطانية للتعليم العالي الني

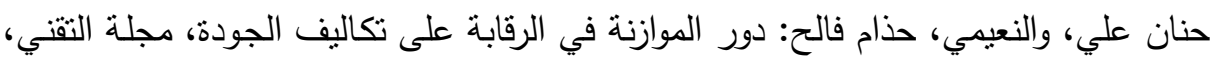

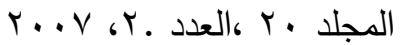

خليل عواد ابو حشيش(r r ب r): محاسبة التكاليف تخطيط ورقابة، دار وائل للنشر 3 .

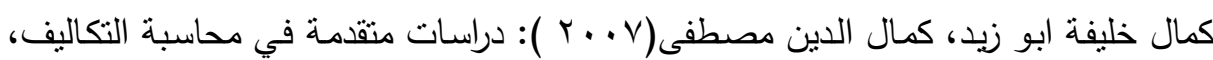
المكتب الجامعي الحديث الاين

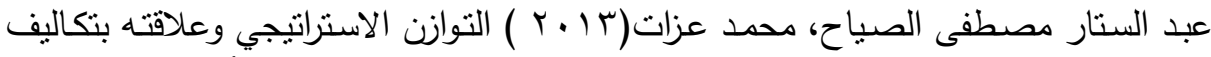

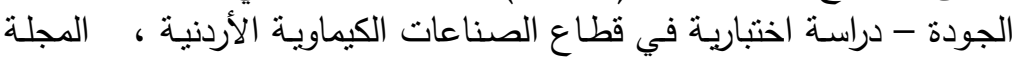

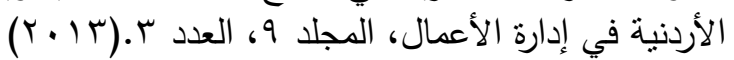

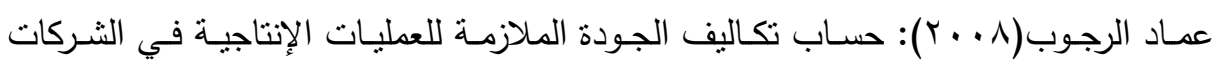

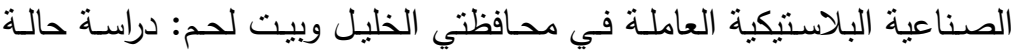

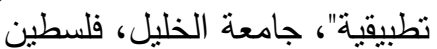

عباس نوار كحيط الموسوي، فاطمة صالح مهدي( • ( ب ) ): التكامل بين إدارة الجودة الثاملة 


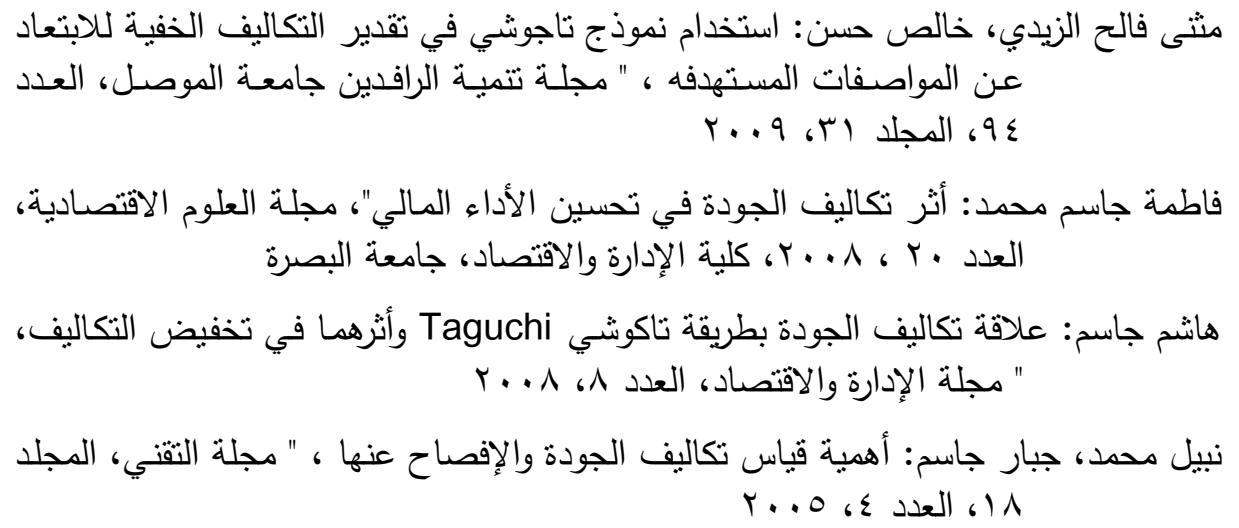

Bisgaard, Soren, "Quality management and Juran's legacy", quality and reliability engineering international, (2008), Volume 77, Number rro

Europian Commission, (2015), Quantifying Quality Costs and the Cost of Poor Quality in Translation, Publications Office of the European Union, Luxembourg.

Hooshim, B. Benjamin, (2009), "Developing quality standards for property management", B. A. Economics and business, University of California, Los angeles.

ISO, (2012), Quality management principles, ISO Central Secretariat, Switzerland.

Kunnanatt, James Thomas, (2009), "Impact of ISO 9000 on organizational climate", International Journal of Manpower, Volume 25, Number

Mullins, Laurie J., (2016), Management and organizational behavior, Fourth edition, Pitman publishing.

Newton, Jethro, (2014), What is quality, 1st European Forum for Quality Assurance, University of Chester, Munich, In 24th November.

Oz, Effy, (2015), Management information systems, sixth edition, Thomson course technology. 
جمال سعد خطاب وآخرون

Schiffauerova, Andrea, and Thomson, Vince, (2010), "A Review of Research on Cost of Quality Models and Best Practices", International Journal of Quality and Reliability Management, Volume $r$, Number

Suarez, J. Gerald, (2011), "Three experts on quality management: Philip B. Crosby, W. Edwards Deming, Joseph M. Juran", Department of navy office, Total quality ledership office.

Taguchi, Genichi, and Chowdhury, Subir, and Wu, Yuin, (2006), Taguchi's Quality Engineering Handbook, John Wiley \& Sons, Inc., Hoboken, New Jersey.

Teli S. N., and Bhushi, U.M., and Surange, V.G., (2012), "Assessment of Cost of poor quality in Automobile Industry", International Journal of Engineering, Volume 2, Number

Uyar, Ali, (2016), "An exploratory study on quality costs in Turkish manufacturing companies", International Journal of Quality and Reliability Management, Volume 25, Number

Wood, Doglas C, (2015), "The executive guide to understanding and implementing quality cost programs", ASQ quality press. 
مجلة العلوم البيئية

معهد الدراسات والبحوث البيئية - جامعة عين شمس لمس لمس

\title{
IMPACT OF THE CONTROL ROLE ON \\ ENVIRONMENTAL COSTS IN ENHANCING THE \\ FINANCIAL PERFORMANCE AND INCREASING \\ THE COMPETITIVE TRAIT FOR INDUSTRIAL \\ COMPANIES
}

\author{
Khtab, G. S. ${ }^{(1)}$; Helmy, E. M. ${ }^{(2)}$; Al-Shaht, T. ${ }^{(1)}$ \\ and Mohamed, M. M. ${ }^{(3)}$ \\ 1) Faculty of Commerce, Ain Shams University 2) National Research
}

3) Faculty of Engineering, Ain Shams University

\begin{abstract}
Sustainable development was the main issue that attracted many countries in the world, and was considered as the basis to save ground our environment for our generations and the coming ones. The awareness of the importance of environmental issues was not only recognized by the developed countries, but rather by underdevelopment ones. The industrial countries were much concerned with this issue because the industrial process has much effect on environment.

As one of the industrial countries, Egypt Arabia showed a great concern to the environmental issues and the Egypt government was most concerned with maintaining its natural resources demanding the private sector to play its role towards the environment.

Based on the above, an empirical study was conducted to study and analysis the environmental costs in the Egypt industrial sector, to highlight the extent of their concern to environmental issues and the nature of the environmental costs conducted by their firms.

The study has begun with an illustration of the environmental pollution and the industrial impacts on environment, and also an
\end{abstract}

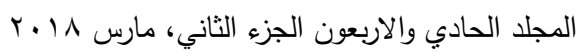


جمال سعد خطاب وآخرون

illustration of the concepts and nature of environmental costs and the methods of dealing with them through a number of previous case studies. However the empirical study depended upon collecting its data study through a survey questionnaire spreads on the industrial sector, which concluded several results such as for example that the most important environmental impacts were gases and waste water, and that most firms are aware of these issues and, therefore, their concern to the environmental issues has increased through advertising and training their employees. The study has also shown that most of the firms don't have especial departments to manage environmental costs because the lake of its output system and the difficulty of tracking these kind of cost. The study also concluded that there were no standard for differentiating between the environmental operating costs and the environmental capital costs, and that the most common accepted cost to this sector was firefighting and radiations costs. 